\title{
Antioxidant Properties of Ergosterol and Its Role in Yeast Resistance to Oxidation
}

\author{
Sebastien Dupont ${ }^{1, *,+}{ }^{\mathbb{D}}$, Paul Fleurat-Lessard ${ }^{2} \mathbb{D}$, Richtier Gonçalves Cruz ${ }^{1,3} \mathbb{D}^{\mathbb{D}}$, Céline Lafarge ${ }^{1}$, \\ Cédric Grangeteau ${ }^{1}\left(\mathbb{D}\right.$, Fairouz Yahou ${ }^{1}$, Patricia Gerbeau-Pissot ${ }^{4}\left(\mathbb{D}\right.$, Odonírio Abrahão Júnior ${ }^{5}$ (D), \\ Patrick Gervais ${ }^{1}$, Françoise Simon-Plas ${ }^{4}$, Philippe Cayot ${ }^{1}$ and Laurent Beney ${ }^{1, *,+} \mathbb{D}$
}

1 UMR Procédés Alimentaires et Microbiologiques, University Bourgogne Franche-Comté, AgroSup Dijon, PAM UMR A 02.102, 21000 Dijon, France; richtier@hotmail.com (R.G.C.); celine.lafarge@agrosupdijon.fr (C.L.); cedric.grangeteau@agrosupdijon.fr (C.G.); yahou.fairouz@gmail.com (F.Y.); gervais@u-bourgogne.fr (P.G.); philippe.cayot@agrosupdijon.fr (P.C.)

2 Institut de Chimie Moléculaire de l'Université de Bourgogne, University Bourgogne Franche-Comté, ICMUB-UMR CNRS 6302, CEDEX, 21078 Dijon, France; Paul.Fleurat-Lessard@u-bourgogne.fr

3 Department Agroindústria, Alimentos e Nutrição, Escola Superior de Agricultura 'Luiz de Queiroz', University of São Paulo, Piracicaba 13418-900, Brazil

4 UMR1347 Agroécologie, ERL 6300 CNRS, INRA, CEDEX, 21065 Dijon, France; Patricia.Gerbeau-Pissot@u-bourgogne.fr (P.G.-P.); francoise.simon-plas@inrae.fr (F.S.-P.)

5 Instituto de Ciências Biológicas e Naturais, Universidade Federal do Triangulo Mineiro, Uberaba 38025-180, Brazil; odonirio.junior@uftm.edu.br

Citation: Dupont, S.; Fleurat-Lessard, P.; Cruz, R.G.; Lafarge, C.; Grangeteau, C.; Yahou, F.; Gerbeau-Pissot, P.; Abrahão Júnior, O.; Gervais, P.; Simon-Plas, F.; et al. Antioxidant Properties of Ergosterol and Its Role in Yeast Resistance to Oxidation. Antioxidants 2021, 10, 1024 https://doi.org/10.3390/ antiox10071024

Academic Editors: Fiorella Biasi and Etsuo Niki

Received: 27 May 2021

Accepted: 22 June 2021

Published: 25 June 2021

Publisher's Note: MDPI stays neutral with regard to jurisdictional claims in published maps and institutional affiliations.

Copyright: (c) 2021 by the authors. Licensee MDPI, Basel, Switzerland. This article is an open access article distributed under the terms and conditions of the Creative Commons Attribution (CC BY) license (https:/ / creativecommons.org/licenses/by/ $4.0 /)$.
* Correspondence: sebastien.dupont@u-bourgogne.fr (S.D.); lbeney@u-bourgogne.fr (L.B.); Tel.: +33-3-80-77-40-97 (S.D.); +33-3-80-77-40-65 (L.B.)

+ These authors contributed equally to this work.

\begin{abstract}
Although the functions and structural roles of sterols have been the subject of numerous studies, the reasons for the diversity of sterols in the different eukaryotic kingdoms remain unclear. It is thought that the specificity of sterols is linked to unidentified supplementary functions that could enable organisms to be better adapted to their environment. Ergosterol is accumulated by late branching fungi that encounter oxidative perturbations in their interfacial habitats. Here, we investigated the antioxidant properties of ergosterol using in vivo, in vitro, and in silico approaches. The results showed that ergosterol is involved in yeast resistance to tert-butyl hydroperoxide and protects lipids against oxidation in liposomes. A computational study based on quantum chemistry revealed that this protection could be related to its antioxidant properties operating through an electron transfer followed by a proton transfer mechanism. This study demonstrates the antioxidant role of ergosterol and proposes knowledge elements to explain the specific accumulation of this sterol in late branching fungi. Ergosterol, as a natural antioxidant molecule, could also play a role in the incompletely understood beneficial effects of some mushrooms on health.
\end{abstract}

Keywords: sterol; oxidation; antioxidant; lipids; yeast; plasma membrane

\section{Introduction}

Since the discovery of cholesterol by Chevreul in the early nineteenth century, a huge diversity of sterols has been identified in the different kingdoms of eukaryotic cells [1]. Ergosterol, the main sterol of fungi, was first isolated from ergot in 1889 [2]. In the second half of the twentieth century, extensive research on sterol functions revealed that the sterols of the four eukaryotic kingdoms (Animalia, Plantae, Fungi, and Protista) are essential for the organization and function of cell plasma membranes [3]. However, the basis of the specificity of sterols in each of the kingdoms is unclear, although it could be related to a supplementary role of some sterols.

Ergosterol is the typical sterol of late branching fungi, and is considered to be the equivalent of cholesterol in vertebrates and of phytosterols (the most representative being 
sitosterol, stigmasterol and campesterol) in plants. Ergosterol is essential to these fungi and its synthetic pathway is one of the main targets of antifungal strategies [4,5]. Even if many aspects of ergosterol biosynthesis regulation are still unknown, it involves a large number of ERG genes and the crosstalk between different environmental signals and pathways [6]. Ergosterol is produced from a biosynthetic pathway that has early steps in common with the cholesterol and phytosterol synthesis pathways, and involves final specific steps that lead to the formation of two conjugated double bonds in the B-ring of the sterol structure (Appendix A). This chemical characteristic is associated with an increased energy and metabolic cost compared with cholesterol and phytosterol synthesis [7]. However, the specificity of sterols in the different living kingdoms is more intricate. Weete and colleagues investigated the diversity of sterols in fungi and showed that ergosterol is the predominant sterol in the most evolved clades of fungi, while cholesterol and other sterols are found in the membranes of early branching fungi [8]. These findings suggest that the evolution of fungi has been accompanied by a tendency to accumulate ergosterol instead of cholesterolrelated sterols. In a previous study, we showed that the final steps of ergosterol synthesis paralleled an increase in the resistance of the yeast Saccharomyces cerevisiae (ascomycota) to desiccation in air [9]. Therefore, we hypothesized that the ergosterol synthetic pathway appeared in late branching fungi during their transition from water to land. Indeed, in contrast to aquatic life, organisms living in interfacial habitats such as the surfaces of soil and rocks, or of living organisms (plants and animals) — particularly those that do not have the possibility of maintaining hydric homoeostasis or of moving to avoid sun injury-are exposed to unstable environmental conditions (temperature, moisture, and light). Some unicellular fungi exhibit remarkable resistance in these habitats, which constitute their main ecological niche. In particular, yeast is able to manage major hydric stress and resist prolonged periods of desiccation [10].

Cellular dehydration results in mechanical and structural constraints on cells, and leads to cell shrinkage, membrane deformation, aggregation of proteins and other contents, and phospholipid phase transitions [11-13]. Cell desiccation also promotes the formation of reactive oxygen species (ROS) by mechanisms related to metabolic arrest and enzyme dysfunction [14,15]. The promotion of oxidation in cells after drying is also directly related to the replacement of the surrounding water by air, because water attenuates light propagation and reduces the lifespan and velocity of ROS such as singlet oxygen more efficiently than air [16]. The cellular mechanisms of yeast adaptation to hydric fluctuations comprise constitutive and inducible processes involved in the management of oxidative and hydric stress. Part of the fungal arsenal to prevent desiccation damage is based on non-specific protective and repair tools also found in other eukaryotes, including catalase and superoxide dismutase. In late branching fungi, ergosterol is also involved in cell resistance to hydric perturbation. Its protective role has been reported to be related to its condensing effect on lipid bilayers, which contributes to the mechanical resistance of the plasma membrane [17]. However, it could also be based on antioxidant properties that prevent the peroxidation of phospholipids. In particular, based on similarities with the mechanism operating in tocopherol, the presence of two double bonds in the B-ring of ergosterol could confer antioxidant properties and thereby provide an adaptive advantage to late branching fungi in interfacial habitats. In a non-cellular context, it was observed that ergosterol protects yogurt from oxidation [18], but the mechanism involved in that effect was not studied. In another study, it was also observed that ergosterol is the main contributor to the antioxidant activity of the lipophilic fraction of button mushrooms [19].

The aim of the present study was to assess the antioxidant properties of ergosterol and to clarify the mechanisms behind the positive contribution of ergosterol to yeast resistance to oxidative treatment. In vitro and in silico approaches allowed us to demonstrate an antioxidant role of ergosterol, which protected the membrane lipids from oxidative perturbation. This property of ergosterol could be involved in the yeast resistance to oxidation. 


\section{Materials and Methods}

\subsection{Yeast Strains and Growth Conditions}

Four strains of $S$. cerevisiae yeast were used in this study. The wild-type strain BY4742 (MAT $\alpha$ his $3 \Delta 1$ leu $2 \Delta 0$ lys $2 \Delta 0$ ura $3 \Delta 0)$ and the $\operatorname{erg} 6 \Delta$ mutant $(M A T \alpha$ his $3 \Delta 1$ leu $2 \Delta 0$ lys2 $\triangle 0$ ::kanMX4) were obtained from the EUROSCARF yeast-deletion library (EUROSCARF, Frankfurt, Germany). The wild-type strain RH448 (MATa leu2 ura3 his4 lys2 bar1) and the $\operatorname{erg} 2 \Delta \operatorname{erg} 6 \Delta$ mutant (MATa erg2(end11)-1 $\triangle:: U R A 3 \operatorname{erg} 6 \Delta$ leu 2 ura3 bar1) were kindly provided by H. Riezman of the University of Geneva [20]. Subculture was performed by introducing one colony of yeast into a $250 \mathrm{~mL}$ conical flask containing $100 \mathrm{~mL}$ of yeast extract-peptone-dextrose (YPD) medium, and was shaken at $250 \mathrm{rpm}$ for $48 \mathrm{~h}$ at $25^{\circ} \mathrm{C}$ on a rotary shaker (New Brunswick Scientific, Edison, NY, USA). Because of the slower growth of the double mutant, a subculture of the erg $2 \Delta \operatorname{erg} 6 \Delta$ mutant was performed for $72 \mathrm{~h}$. Then, $1 \mathrm{~mL}$ of subculture was transferred into a flask containing $100 \mathrm{~mL}$ of fresh YPD medium, and the cultures were shaken at $250 \mathrm{rpm}$ for $24 \mathrm{~h}$ at $25^{\circ} \mathrm{C}$, and were allowed to grow to the early stationary phase. This time was increased to $48 \mathrm{~h}$ for the $\operatorname{erg} 2 \Delta \operatorname{erg} 6 \Delta$ strain. A stationary phase of growth was chosen because yeasts are generally more resistant to various perturbations, including oxidative treatments, than they can be in the exponential phase [21,22]. The final population was estimated at about $10^{8}$ cells $\mathrm{mL}^{-1}$. Samples $(20 \mathrm{~mL})$ of cultures were centrifuged ( $5 \mathrm{~min}, 2800 \times g)$, washed twice in phosphate-buffered saline (PBS), and the cell concentration was adjusted to $\mathrm{OD}_{600 \mathrm{~nm}}=0.5$.

\subsection{Sterol and Fatty Acid Analysis of the Different Strains of Yeast}

For the total fatty acid analysis, transmethylation of fatty acids was performed for $1 \mathrm{~h}$ at $85^{\circ} \mathrm{C}$ by mixing a yeast pellet (number of yeasts was assessed by flow cytometry for each pellet of the different strains of yeasts) with $1 \mathrm{~mL}$ of methanol: $\mathrm{H}_{2} \mathrm{SO}_{4}$ solution $(100: 2.5, v / v)$ containing the internal standards C17:0 $(6.3 \mathrm{mg} / \mathrm{mL})$. After cooling, $800 \mu \mathrm{L}$ of hexane:2.5\% $\mathrm{NaCl}(1: 1, v / v)$ was added, and the upper hexane phase containing fatty acid methyl esters (FAMEs) was harvested and injected in a GC-FID chromatograph. GCFID was performed using an Agilent 7890 gas chromatograph equipped with a DB-Wax column ( $15 \mathrm{~m} \times 0.53 \mathrm{~mm}, 1 \mu \mathrm{m}$; Agilent, Santa Clara, CA, USA) and flame ionization detection. The temperature gradient was $160^{\circ} \mathrm{C}$ for $1 \mathrm{~min}$, increased to $190^{\circ} \mathrm{C}$ at $20^{\circ} \mathrm{C} / \mathrm{min}$, increased to $210^{\circ} \mathrm{C}$ at $5{ }^{\circ} \mathrm{C} / \mathrm{min}$, and then remained at $210^{\circ} \mathrm{C}$ for $5 \mathrm{~min}$. The FAMEs were identified by comparing their retention times with the commercial fatty acid standards (Sigma-Aldrich, Saint Quentin Fallavier, France) and were quantified using ChemStation (Agilent) to calculate the peak surfaces, which were then compared with the C17:0 response.

For the sterol analysis, a saponification step was performed by adding $1 \mathrm{~mL}$ of ethanol and $0.1 \mathrm{~mL}$ of $11 \mathrm{~N} \mathrm{KOH}$ with the internal standard a-cholestanol $(50 \mu \mathrm{g} / \mathrm{mL})$ to a yeast pellet and incubating it overnight at $80^{\circ} \mathrm{C}$. After the addition of $1 \mathrm{~mL}$ of hexane and $2 \mathrm{~mL}$ of water, the sterol-containing upper phase was recovered, and the solvent was evaporated under an $\mathrm{N}_{2}$ gas stream. The sterols were trimethylsilylated by $\mathrm{N}, \mathrm{O}-$ bis(trimethylsilyl) trifluoroacetamide (BSTFA)-trimethylchlorosilane for $15 \mathrm{~min}$ at $115^{\circ} \mathrm{C}$. After complete evaporation of BSTFA under $\mathrm{N}_{2}$ gas, the derivatized sterols were dissolved in $0.4 \mathrm{~mL}$ of hexane and were analyzed by GC-MS. GC-MS was performed using an Agilent 6850 gas chromatograph and coupled MS detector MSD 5975-EI (Agilent). An HP-5MS capillary column (5\% phenyl-methyl-siloxane, 30-m, 250-mm, and 0.25-mm film thickness; Agilent) was used with helium carrier gas at $2 \mathrm{~mL} / \mathrm{min}$; injection was done in splitless mode; the injector and mass spectrometry detector temperatures were set to $250^{\circ} \mathrm{C}$; and the oven temperature was held at $50{ }^{\circ} \mathrm{C}$ for $1 \mathrm{~min}$, then programmed with a $25^{\circ} \mathrm{C} / \mathrm{min}$ ramp to $150{ }^{\circ} \mathrm{C}$ (2-min hold) and a $10^{\circ} \mathrm{C} / \mathrm{min}$ ramp to $320^{\circ} \mathrm{C}$ (6-min hold).

\subsection{Assessment of Oxidation Effects on Yeast Viability and Plasma Membrane Integrity}

The oxidation effects on yeast physiology and viability were investigated after the induction of a free-radical reaction by tert-butyl hydroperoxide (t-BOOH). Yeasts were placed in PBS containing t-BOOH (4 or $6 \mathrm{mM}$ ) for 1 or $2 \mathrm{~h}$. After these times, the cells 
were washed and their viability was assessed by the colony forming unit (CFU) method. Plasma membrane integrity was also measured by adding $2 \mu \mathrm{L}$ of propidium iodide (PI) solution $(1 \mathrm{mg} / \mathrm{mL})$ to $1 \mathrm{~mL}$ of yeast $\left(\mathrm{OD}_{600 \mathrm{~nm}}=0.5\right)$. PI crossed the plasma membrane of permeabilized cells and stained the nucleic acids. The proportion of stained cells was estimated by flow cytometry using a BD FACS Aria II Flow Cytometer (BD Biosciences, San José, CA, USA) equipped with a laser excitation line at $488 \mathrm{~nm}$. PI fluorescence was detected at $610 \mathrm{~nm}$ with at least 10,000 cells included in each analysis.

\subsection{Preparation of Liposomes from Natural Yeast Lipid Extracts}

Liposomes were prepared from natural yeast polar lipid extracts of S. cerevisiae (Avanti Polar Lipids) using the film hydration method [23]. The phospholipids and the different sterols (zymosterol, cholesta-5,7,24-trienol (Avanti Polar Lipids), and ergosterol (Sigma)) were dissolved in chloroform. The organic solvent was evaporated to form a film that was dried under a stream of nitrogen for $1 \mathrm{~h}$. This film was then hydrated with degassed PBS to obtain multilamellar vesicles. PBS was degassed of oxygen by nitrogen bubbling for $12 \mathrm{~h}$. We prepared large unilamellar vesicles from the multilamellar ones using the extrusion technique. The suspension of multilamellar vesicles was transferred into a Liposofast small-volume extrusion device (Avestin Inc., Ottawa, ON, Canada) with a polycarbonate membrane with a $200 \mathrm{~nm}$ pore size, designed to obtain a homogeneous population of large unilamellar liposomes. The lipid concentration of the liposomes made only with yeast lipid extracts was $2.5 \mathrm{mM}$. For liposomes containing sterols, zymosterol, cholesta-5,7,24-trienol, or ergosterol was added to obtain a final concentration of $0.83 \mathrm{mM}$. This corresponds to a sterol/phospholipid molar ratio of $1 / 3$. A control was also performed by adding tocopherol, a lipophilic antioxidant, in the same ratio of the one of sterols.

\subsection{Assessment of Liposome Fluidity by Fluorescence Spectroscopy}

The membrane fluidity of the different liposomes was assessed by steady-state fluorescence anisotropy of diphenyl-hexatriene (DPH). For that, $600 \mu \mathrm{L}$ of the previously prepared liposome suspension was transferred to a quartz cuvette containing $2400 \mu \mathrm{L} \mathrm{PBS}$. The liposomes were labelled with DPH ( $1 \mu \mathrm{L}$ of $5 \mathrm{mM}$ stock solution in tetrahydrofuran) in a dark at $25{ }^{\circ} \mathrm{C}$ for $5 \mathrm{~min}$.

Steady-state anisotropy of DPH was measured in a Fluorolog-3 spectrometer (Horiba Jobin Yvon) using T-format fluorescence polarizers. During the measurements, samples were stirred and equilibrated in a temperature-controlled chamber using a thermoelectric Peltier junction. The excitation and emission wavelengths were $360 \mathrm{~nm}$ ( $5 \mathrm{~nm}$ bandwidth) and $431 \mathrm{~nm}$ (5 nm bandwidth), respectively. Steady-state fluorescence anisotropy (r) was calculated as follows:

$$
r=\frac{I_{V V}-G I_{V H}}{I_{V V}+2 G I_{V H}}
$$

where $I$ is the fluorescence intensity, and the first and second subscripts refer to the setting of the excitation and emission polarizers, respectively. $G=\frac{I_{H V}}{I_{H H}}$ is a correction factor for the monochromator's transmission efficiency for vertically and horizontally polarized light.

\subsection{Oxidation of Liposome Suspensions and Assessment of Lipid Peroxidation}

The kinetics of lipid peroxidation were followed using the fluorescent probe C11BODIPY 581/591 (C11-BP) at a final concentration of $20 \mu \mathrm{M}$. Liposomes were stained with the probe for $10 \mathrm{~min}$ before starting the oxidation treatments. Analyses were performed with a Fluorolog-3 spectrofluorimeter (Horiba Jobin Yvon). The excitation wavelength was set at $488 \mathrm{~nm}$ and the emission intensity ratio between the oxidized (520 nm) and the non-oxidized $(591 \mathrm{~nm})$ state of the probe was measured. During the measurements, the samples were stirred and equilibrated at $25^{\circ} \mathrm{C}$ in a temperature-controlled chamber using a thermoelectric Peltier junction.

The oxidation of liposomes was induced by free-radical reactions. Lipid peroxidation was generated by the addition of $150 \mu \mathrm{L}$ of $2 \mathrm{mM}$ cumene hydroperoxide and 
$15 \mu \mathrm{L}$ of $0.1 \mathrm{mM}$ haemin. Emission spectra of C11-BP were acquired every $900 \mathrm{~s}$ and the

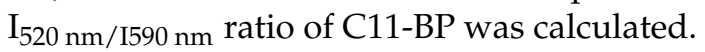

\subsection{Assessment Hydrogen Atom-Donating Ability of Sterols by the DPPH Method}

The DPPH method is based on the exchange of a proton and a single electron (radical), between the stable radical chromophore 2,2-diphenyl-1-picrylhydrazyl $\left(\mathrm{DPPH}^{\bullet}\right)$, and a molecule (A-H), generally an antioxidant; here, a sterol: $\mathrm{DPPH}^{\bullet}+\mathrm{A}-\mathrm{H} \rightarrow \mathrm{DPPH}-\mathrm{H}+\mathrm{A}^{\bullet}$. The radical DPPH ${ }^{\bullet}$ absorbs at $\lambda_{\max }=515 \mathrm{~nm}\left(\mathrm{E}=10,900 \mathrm{M}^{-1} \cdot \mathrm{cm}^{-1}\right.$ in methanol $)$ and gives a purple solution, generally in acetone, methanol, or ethanol (appropriate solvents of $\left.\mathrm{DPPH}^{\bullet}\right)$. The non-radical DPPH-H resulting from the radical exchange with a molecule absorbs in the UV and gives a yellow solution. The observation of the decrease in optical density (OD) at $515 \mathrm{~nm}$ is usually carried out over a period of between $10 \mathrm{~min}$ [24] and a maximum of $300 \mathrm{~min}$ [25].

In our experiments, ergosterol $(\log P=9.28)$ and zymosterol $(\log P=9.32)$ were not soluble in ketone or alcohols, even in long-chain alcohols such as octanol and decanol, and the usual solvents for the $\mathrm{DPPH}^{\bullet}$ method cannot be used to evaluate the potential ability of sterol to scavenge a radical. The sterols were easily dissolved in isooctane (2,2,4-trimethylpentane), a non-polar solvent; $7 \mathrm{mg}$ of $\mathrm{DPPH}^{\bullet}$ was dissolved in $100 \mathrm{~mL}$ of isooctane $\left(1.7 \times 10^{-4} \mathrm{M}\right)$ to obtain an $\mathrm{OD}_{515 \mathrm{~nm}}$ around 1 after a 1:1 dilution. Because $\mathrm{DPPH}^{\bullet}$ is poorly soluble in isooctane, an overnight dissolution in a screw-capped vial was necessary. Zymosterol and ergosterol solutions at different concentrations in isooctane were mixed $1 / 1$ with the $\mathrm{DPPH}^{\bullet}$ solution to obtain kinetics at molar ratios of sterol/DPPH ${ }^{\bullet}$ from 0.1 to 5 . The solutions of the $\mathrm{DPPH}^{\bullet}$ and sterols were stored in a screw-capped vial until the $\mathrm{OD}_{515 \mathrm{~nm}}$ reached a stable value. Regular samplings were performed to follow the $\mathrm{OD}_{515 \mathrm{~nm}}$ during this time. Concerning statistical analysis, the experiments to obtain each point for the zymosterol at the different times were repeated three times, allowing us to calculate the $95 \%$ confidence intervals. For the ergosterol, the reaction kinetic was much faster and the different points were not obtained at the same time. We could not therefore calculate the confidence intervals for these points. So, we made the choice to show all of the obtained points (30) on the figure, in order to model them and to validate the modeling via a Pearson table.

The kinetics obtained at different ratios allowed us to calculate the $\mathrm{EC}_{50}$ and $\mathrm{t}_{50}$ values, corresponding to the respective effective concentrations of sterol, giving a final $\mathrm{OD}_{515} \mathrm{~nm}$ of $50 \%$ of the initial $\mathrm{OD}_{515} \mathrm{~nm}$ and the time required to reach the steady state with $\mathrm{EC}_{50}$. For each sterol/DPPH ${ }^{\bullet}$ ratio, the $\mathrm{OD}_{515} \mathrm{~nm}$ at infinity was determined from the graphic representations of $\mathrm{OD}_{515 \mathrm{~nm}}$ as a function of time. Then, the graphic representation of the $\mathrm{OD}_{515 \mathrm{~nm}}$ at infinity as a function of the different sterol/DPPH ${ }^{\bullet}$ ratios was plotted. From this, the concentration required for an $\mathrm{OD}_{515 \mathrm{~nm}}$ at infinity of 0.5 was determined, corresponding to the $\mathrm{EC}_{50}$ value; $\mathrm{t}_{50}$ was then calculated. These two parameters allowed us to calculate the radical scavenging efficiency (RSE) as the inverse of the product of $\mathrm{EC}_{50}$ and $t_{50}$ [26]: $R S E=1 /\left(E C_{50} t_{50}\right)$. The less time necessary to reach the end of the radical exchange, the lower the concentration of the molecule required to halve the initial $\mathrm{OD}_{515} \mathrm{~nm}$ value (i.e., halve the initial concentration of radical $\mathrm{DPPH}^{\bullet}$ ), and the higher the RSE value, the better the radical scavenger of sterol.

\subsection{Computational Analysis of Antioxidant Properties of Sterols}

The computational study was conducted on ergosterol, zymosterol, and cholesta5,7,24-trienol. The structure of ergosterol in its bioactive conformation was obtained from the complex with an elicitin enzyme, specifically the secreted $\beta$-cryptogenin from Phytophthora cryptogea, whose crystallographic structure with the sterol was obtained in 1998 [27]. The structures of zymosterol and cholesta-5,7,24-trienol were obtained by modifying the structure obtained for ergosterol. The structures were optimized in solvent ethyl ethanoate, simulated from its dielectric constant of 5.9867 with the continuous polarized integral equation formalism polarizable continuum model (IEF-PCM model) [28]. Ethyl ethanoate 
was used as a solvent to mimic a biological lipid environment. The B3LYP DFT method with a 6-311+ G (2d,p) basis set was used in the Gaussian 16 program [29].

The radical cations were obtained by changing the charge and multiplicity in the input for unrestricted calculations of the oxidized molecules. The spin density of the oxidized molecules (minimized after the withdrawal of an electron) were plotted with ChemCraft [30] to evaluate the electronic delocalization of the unpaired electron. The electrostatic potential map was plotted using Gabedit [31] on the electronic density isosurface of 0.001 , where blue indicates more positive regions and red the most negative regions. The final radical product was then obtained from the radical cations by deleting one $\mathrm{H}$ atom. Many positions were tried to subtract these hydrogen atoms-all of them are shown in Appendix A, while only the most stable ones are shown here for ergosterol, zymosterol, and cholesta-5,7,24-trienol.

\section{Results}

\subsection{Sterol and Fatty Acid Composition of the Different Yeast Strains}

Deletion of the genes involved in the ergosterol biosynthetic pathway has been described to strongly affect the nature of sterols accumulated by yeasts [32]. It exists only five viable mutants (cultivable without specific accommodations of a classical growth yeast medium) with single gene deletion in the ergosterol biosynthetic pathway (EBP): $\operatorname{erg} 6 \Delta, \operatorname{erg} 2 \Delta, \operatorname{erg} 3 \Delta, \operatorname{erg} 5 \Delta$, and $\operatorname{erg} 4 \Delta$. The successive action of the enzymes linked to these genes allows for the formation of ergosterol in wild type strains. In our study, the erg6 $6 \Delta$ strain was chosen, because erg6 is the first non-essential gene encoding for the enzyme that catalyzes the first of the five final steps of the EBP (See Appendix A). This strain accumulates mainly zymosterol, a sterol whose structure is very different from ergosterol, and cholesta-5,7,24-trienol, a sterol that exhibits two conjugated double bonds as ergosterol [20]. The $\operatorname{erg} 2 \Delta \operatorname{erg} 6 \Delta$ double mutant was used in our study because it accumulates a large majority of zymosterol [20]. However, the sterol and fatty acid composition can be modified by growth conditions of yeasts. Sterols and fatty acids accumulated by the wild type and EBP mutant strains of our study were analyzed and are presented in Figure 1.

Ergosterol was the main sterol accumulated by the two wild type strains of yeasts. Its proportion reached $77 \%$ and $88 \%$ for the BY4742 and RH448 strains, respectively (Figure 1a). The $\operatorname{erg} 2 \Delta \operatorname{erg} 6 \Delta$ mutant accumulated mainly zymosterol (94\%). Three main sterols were accumulated in the erg $6 \Delta$ mutant, namely: $46 \%$ of cholesta-5,7,24-trienol, $25 \%$ of zymosterol, and $24 \%$ of cholesta-5,7,22,24-tetraenol. These proportions of sterols for the different strains were in agreement with previous studies of the literature. Concerning the fatty acid composition, the two wild type strains presented a similar profile with the following four main fatty acids: $\approx 45 \%$ of palmitoleic acid (C16:1), $\approx 30 \%$ of oleic acid (C18:1), $\approx 17 \%$ of palmitic acid (C16:0), and $\approx 5 \%$ of stearic acid (C18:0; Figure $1 \mathrm{~b}$ ). The deletion of EBP genes had little effect on the relative proportions of fatty acids. The fatty acid profile of the $\operatorname{erg} 6 \Delta$ mutant was close to the ones of the wild type strains. For the $\operatorname{erg} 2 \Delta \operatorname{erg} 6 \Delta$ mutant, the only slight difference consisted of a decrease of oleic acid $(20 \%)$ and an increase of myristic acid (C14:0) (5\%).

\subsection{Wild-Type (WT) Yeasts Are More Resistant to Oxidative Treatment Than erg6 6 and $\operatorname{erg} 2 \Delta \operatorname{erg} 6 \Delta$ Strains}

The effect of the molecular species of sterol on yeast resistance to oxidative perturbation was assessed by cell exposition to $\mathrm{t}-\mathrm{BOOH}$, an oxidizing agent that initiates membrane lipid oxidation. The cultivability and plasma membrane integrity of both strains were measured after oxidative treatment with t-BOOH ( 4 or $6 \mathrm{mM}$ ) for 1 or $2 \mathrm{~h}$ (Figure 2).

The $\operatorname{erg} 2 \Delta \operatorname{erg} 6 \Delta$ mutant was very sensitive to $\mathrm{t}-\mathrm{BOOH}$ treatments. No cultivable cells were observed after the different treatments, even for the less severe one $(4 \mathrm{mM}, 1 \mathrm{~h})$. The $\operatorname{erg} 6 \Delta$ strain was also more sensitive to this treatment than the WT strains. The viability of the $\operatorname{erg} 6 \Delta$ mutant strain was $77 \%$ and $26 \%$ after 1 and $2 \mathrm{~h}$ treatment, respectively, with $4 \mathrm{mM}$ $\mathrm{t}-\mathrm{BOOH}$, and $41 \%$ and $0.9 \%$ after 1 and $2 \mathrm{~h}$ treatment, respectively, with $6 \mathrm{mM} \mathrm{t}-\mathrm{BOOH}$ 
(Figure 2a). Therefore, the decrease in the viability of this strain was dependent on the concentration of $\mathrm{t}-\mathrm{BOOH}$ and the contact time. The viability of the BY4742 and RH448 WT strains decreased to $66 \%$ and $68 \%$, respectively, after the most severe treatment $(6 \mathrm{mM}$, $2 \mathrm{~h}$; Figure 2a). A complementary approach to assess yeast sensitivity was performed by plating yeasts onto solid growth media containing different concentrations of $\mathrm{t}-\mathrm{BOOH}$ (Appendix B). The higher sensitivity of the mutant strains in comparison with the wild type strains has been confirmed.

(a)
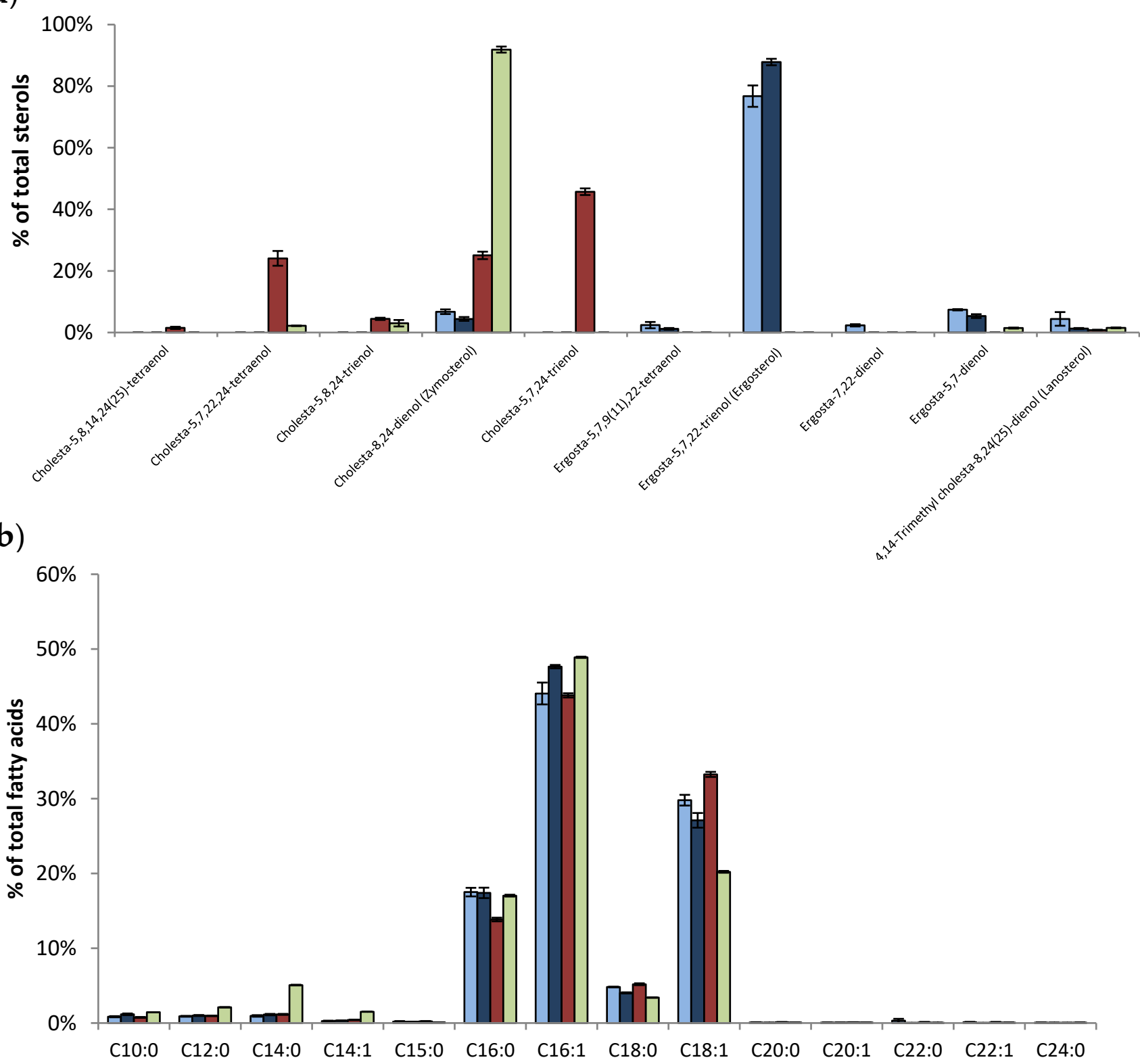

Figure 1. Lipid composition of the different S. cerevisiae strains. BY4742 WT ( $\square)$, RH448 WT ( $\square)$, erg6 $(\square)$, and erg2 $\Delta$ erg6 $\Delta$ $(\square)$ strains of S. cerevisiae. (a) Analysis of the sterol composition and the relative abundance. (b) Analysis of the fatty acid composition and the relative abundance. Vertical bars represent standard deviation. 
(a)

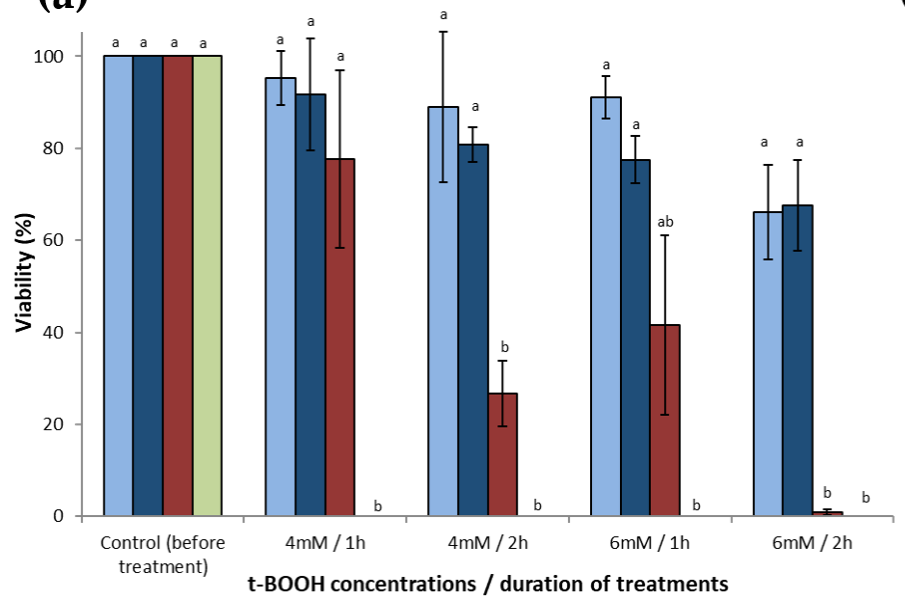

(b)

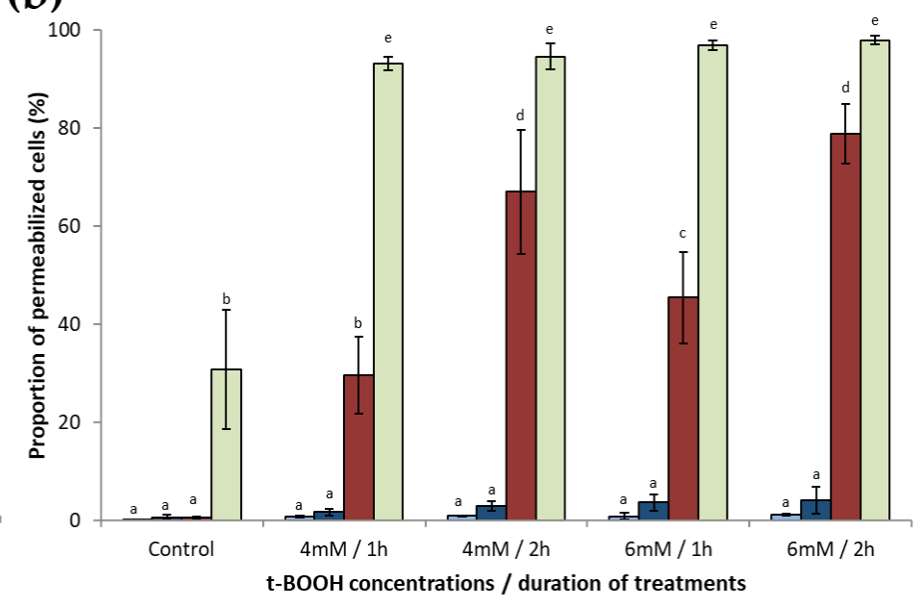

Figure 2. Resistance of $S$. cerevisiae to treatment with t-BOOH. After growth in the early stationary phase, BY4742 WT ( $\square$ ), RH448 WT $(\square), \operatorname{erg} 6 \Delta(\square)$, and $\operatorname{erg} 2 \Delta \operatorname{erg} 6 \Delta(\square)$ strains of $S$. cerevisiae were washed, adjusted to a concentration corresponding to $\mathrm{DO}_{600 \mathrm{~nm}}=0.5$, and placed in PBS containing t-BOOH (4 or $\left.6 \mathrm{mM}\right)$ for 1 or $2 \mathrm{~h}$. (a) After treatment, the cells were washed and spotted at different ten-fold dilutions (from $10^{-1}$ to $10^{-4}$ ) to assess the cell viability. (b) Plasma membrane integrity was assessed by PI staining of cells and flow cytometry analysis. Data are presented as mean values \pm standard deviation of three independent experiments. ANOVA was performed on R v3.6.1 software and if it was significant $(p<0.01)$, Tukey's HSD (Honest Significant Difference) test was performed to observe significant differences among conditions. Letters a, b, $c$, $\mathrm{d}$, and e represent significantly different groups.

Plasma membrane integrity was also evaluated for both strains after treatment with $\mathrm{t}-\mathrm{BOOH}$ (Figure $2 \mathrm{~b}$ ). The membrane integrity of the $\operatorname{erg} 2 \Delta \operatorname{erg} 6 \Delta$ strain was strongly affected after $\mathrm{t}-\mathrm{BOOH}$ treatments. The proportion of permeabilized cells was higher than $95 \%$ after the different treatments. We also observed that the control cells (without $\mathrm{t}-\mathrm{BOOH}$ treatment) of this double mutant presented approximately $30 \%$ of permeabilized cells, indicating an initial fragility of the cells without oxidative treatments. For the erg $6 \Delta$ strain, the proportion of permeabilized cells increased with the concentration of $\mathrm{t}-\mathrm{BOOH}$ and the duration of treatment to reach $79 \%$ after $2 \mathrm{~h}$ treatment with $6 \mathrm{mM}$ t-BOOH. The membrane integrity of the WT strains was hardly affected by any of the treatments.

The viability and membrane integrity results indicate that the decrease of yeast survival during t-BOOH treatment was mainly related to plasma membrane permeabilization.

\subsection{Sterols Protect Lipids from Oxidation in Liposomes}

The results obtained with the WT and EBP mutant strains suggested that ergosterol is involved in yeast resistance to oxidative perturbation. To clarify the role of ergosterol, liposomes prepared from natural polar lipid extracts of $S$. cerevisiae containing zymosterol (accumulated by the $\operatorname{erg} 6 \Delta$ and $\operatorname{erg} 6 \Delta \operatorname{erg} 2 \Delta$ strains), cholesta-5,7,24-trienol (accumulated by the $\operatorname{erg} 6 \Delta$ strain), or ergosterol (accumulated by wild type strains) were subjected to oxidative perturbation. The kinetics of lipid peroxidation were assessed using the ratiometric fluorescent probe C11-BODIPY 581/591 (C11-BP) [33].

Oxidative perturbation was induced by adding cumene hydroperoxide and haemin to the liposome suspension (Figure 3a). An increase in the $\mathrm{I}_{520 \mathrm{~nm}} / \mathrm{I}_{590} \mathrm{~nm}$ ratio of C11-BP fluorescence corresponded with an increase in lipid peroxidation. Five compositions of liposomes were tested, as follows: with ergosterol, cholesta-5,7,24-trienol, or zymosterol; without sterol; and with tocopherol, a well-known antioxidant that was used as a control. Liposomes prepared without sterols exhibited the fastest oxidation kinetics with a final ratio of C11-BP, close to 57 after $3400 \mathrm{~s}$ (Figure 3a). When zymosterol, cholesta-5,7,24trienol, or ergosterol were added during liposome preparation, the kinetics of oxidation were slowed and the final ratios were decreased to 33.1, 14.5, and 24.5, respectively. Lipid 
peroxidation was drastically reduced in the liposomes containing tocopherol, with a final ratio of 5.5.

(a)

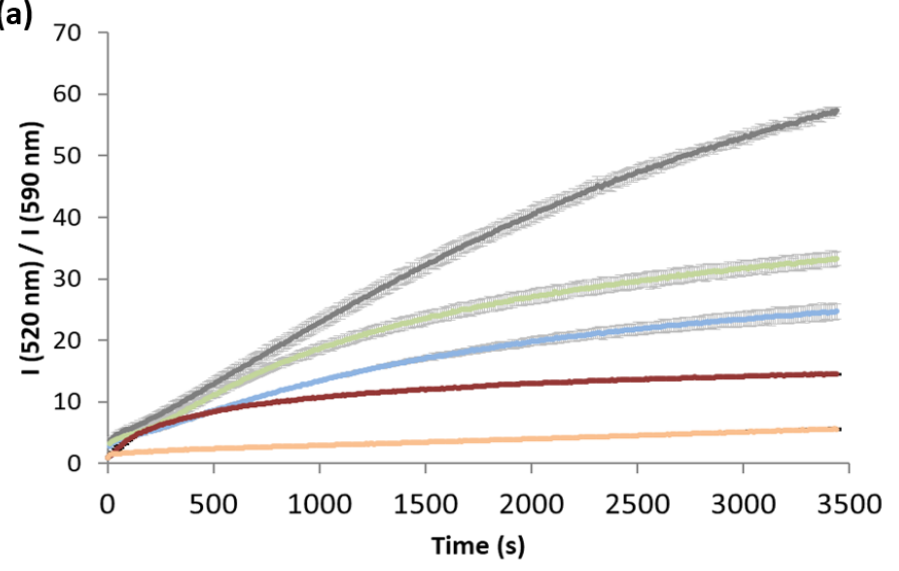

(b)

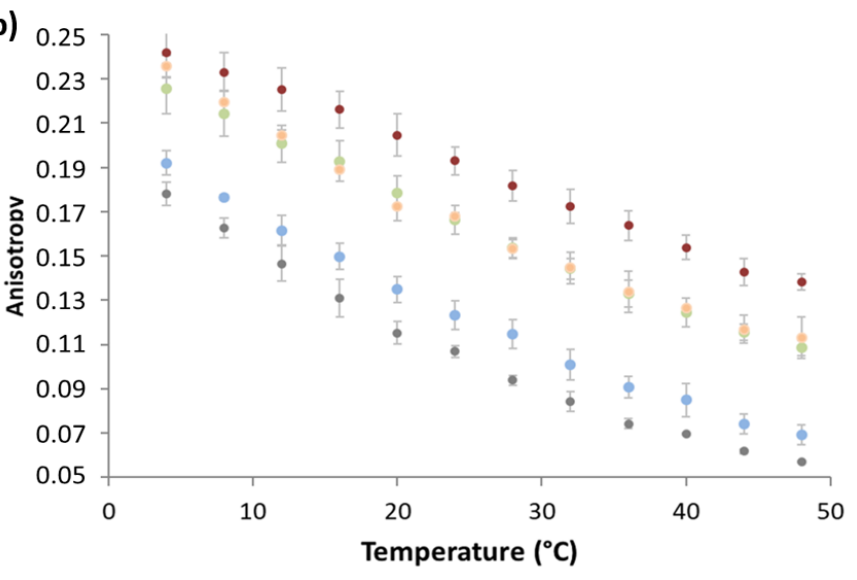

Figure 3. Effect of the sterol content of the liposome properties. Liposomes were made from yeast lipid extracts without sterol (๑), with a zymosterol/phospholipid molar ratio of $1 / 3(\odot)$, with a cholesta-5,7,24-trienol/phospholipid molar ratio of $1 / 3(\bullet)$, or with an ergosterol/phospholipid molar ratio of $1 / 3(\bullet)$. Control experiments were performed with lipososmes with a tocopherol/phospholipid molar ratio of $1 / 3(\odot)$. (a) Phospholipid oxidation induced by cumene hydroperoxide and haemin was assessed by the oxidation kinetics of BP-C11 in liposomes with different sterol compositions. Oxidation was expressed as the intensity ratio $\left(\mathrm{I}_{520} \mathrm{~nm}\right)_{\text {oxidized }} /\left(\mathrm{I}_{590} \mathrm{~nm}\right)_{\text {non-oxidized }}$. Oxidation was started at $\mathrm{t}=0 \mathrm{~s}$. (b) Fluidity of liposomes was assessed by steady-state DPH fluorescence anisotropy measurement as a function of temperature in the range $4-48^{\circ} \mathrm{C}$. The results are presented with error bars corresponding to the standard deviation calculated from three repeated experiments.

Sterols are known to differentially affect the membrane structure, packing, and fluidity. Rigidification of the lipid bilayer of liposomes by sterols could play a role in the protection of phospholipids against oxidation by reducing the accessibility and the mobility of radical species to the core of the membrane. To test this hypothesis, the fluidity and structure of the liposomes were assessed by fluorescence anisotropy after lipid bilayer staining with DPH (Figure 3b). Steady-state fluorescence anisotropy measurements were performed over a range of temperatures between $4{ }^{\circ} \mathrm{C}$ and $48{ }^{\circ} \mathrm{C}$. Independent of the composition of the liposomes, decreasing the temperature led to a progressive increase in anisotropy, reflecting the global rigidification of the lipid bilayer without net lipid phase transition. The absence of a net lipid phase transition is probably related to the diversity of phospholipids in yeast lipid extracts: each type of phospholipid displays a specific phase transition temperature. However, the global rigidity of the liposomes depended on the presence of sterols or tocopherol. Sterols increased bilayer rigidity at a given temperature with an effect depending on the nature of sterols: cholesta-5,7,24-trienol > zymosterol > ergosterol. Tocopherol showed similar stiffening properties to zymosterol.

\subsection{Ergosterol Displays Greater 2,2-Diphenyl-1-Picrylhydrazyl (DPPH) Radical-Scavenging Activity Than Zymosterol}

The DPPH method is widely used to assess the radical-scavenging activity of molecules. This method is based on the reduction of the optical density at $515 \mathrm{~nm}$, the maximum wavelength of the radical chromophore $\mathrm{DPPH}^{\bullet}$. The kinetics of the radical scavenging activity of zymosterol and ergosterol are presented in Figure 4a,b, respectively. Cholesta$5,7,24$-trienol, which is a very expensive molecule, was not used because the DPPH method requires huge quantities of sterols. 
(a)

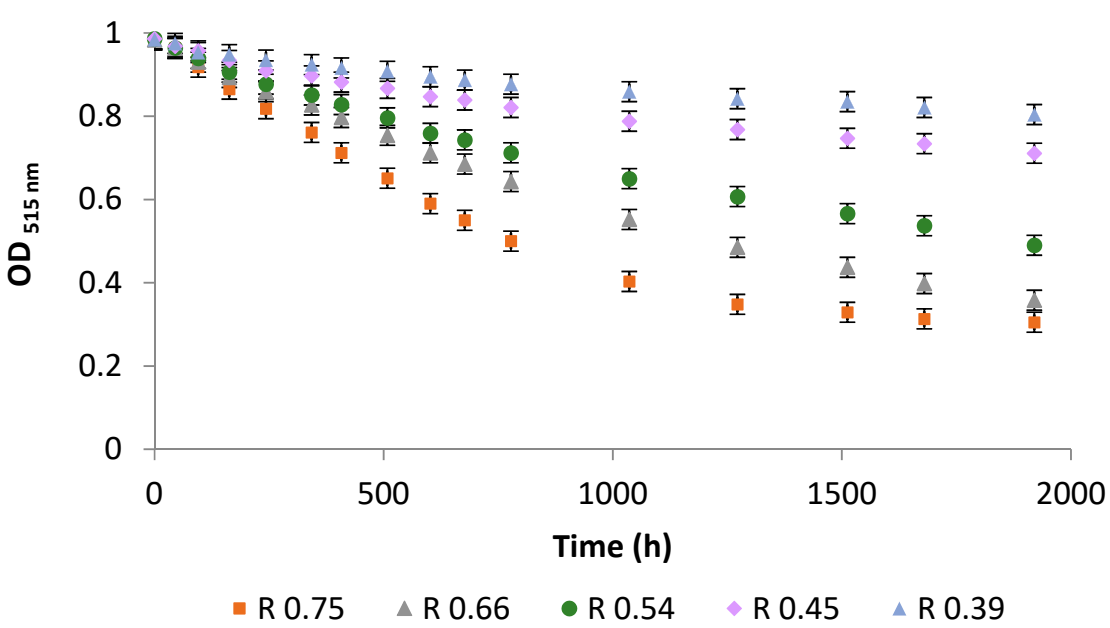

(b)

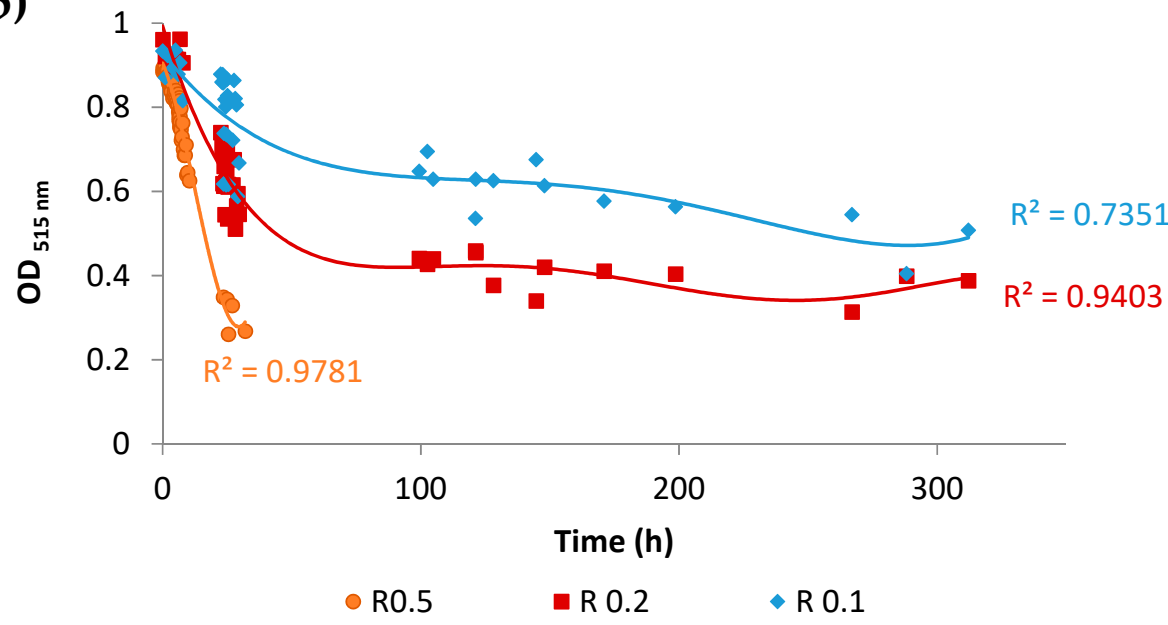

Figure 4. Assessment of the anti-oxidant activity of sterols using the stable free radical diphenylpicrylhydrazyl (DPPH). (a) Kinetics of the decrease of the absorbance at $515 \mathrm{~nm}$ for different zymosterol/DPPH ${ }^{\bullet}$ ratios (R). Error bars represent the $95 \%$ confidence interval. (b) Kinetics of the decrease of the absorbance at $515 \mathrm{~nm}$ for different ergosterol/DPPH${ }^{\bullet}$ ratios (R). Each of the kinetics were modelled by polynomial law (30 points per kinetic). With the Pearson's table (critical values of correlation coefficient), using a value of level of significance for a two-tailed test of 0.001 , and with 30 points (freedom degree $=28$ ), the critical $r$ value is 0.570 . The values of regression coefficients reflect a suitable fit.

Nearly $33 \mathrm{~h}$ (around $2000 \mathrm{~min}$ ) are necessary to exchange all radicals, with an ergosterol/DPPH ratio of 0.5 , versus $2000 \mathrm{~h}$ (nearly 2 months) with a zymosterol/DPPH ratio of 0.54 . These results clearly demonstrate that ergosterol is a much more efficient radical scavenger than zymosterol. The antioxidant activity measured by the DPPHscavenging method is often reported as (i) $\mathrm{EC}_{50}$, defined as the effective concentration of the antioxidant necessary to decrease the initial DPPH concentration by $50 \%$, and (ii) $t_{50}$, the time needed to reach the steady state with $\mathrm{EC}_{50}$. Based on the kinetics at 25 different zymosterol/DPPH ratios, and after extended storage and OD recording (more than 2 months to reach a stable final value; data not shown), the $\mathrm{EC}_{50}$ was determined to be $5.2 \times 10^{-5} \pm 3 \times 10^{-7} \mathrm{M}$ and $\mathrm{t}_{50}$ to be around $1417 \pm 404 \mathrm{~h}$ (five zymosterol/DPPH ratios are presented in Figure 4a). Using the kinetics at 30 different ergosterol/DPPH ratios (data not shown), the $\mathrm{EC}_{50}$ was determined to be $1.1 \times 10^{-5} \pm 6.4 \times 10^{-8} \mathrm{M}$ and $\mathrm{t}_{50}$ around $300 \pm 17 \mathrm{~h}$ (three ergosterol/DPPH ratios are presented in Figure $4 \mathrm{~b}$ ). The radical scavenging efficiency (RSE) for ergosterol was much higher than that for zymosterol, with respective values of $5.1 \pm 0.3 \mathrm{~L} \mathrm{~mol}^{-1} \mathrm{~min}^{-1}$ and $0.24 \pm 0.07 \mathrm{~L} \mathrm{~mol}^{-1} \mathrm{~min}^{-1}$. 


\subsection{Computational Analysis of Antioxidant Properties of Sterols}

To understand the role of sterols in the prevention of phospholipid oxidation, we must consider the possible reactions between sterols and free radicals $\left(R^{\bullet}\right)$. Four reaction-type mechanisms are possible:

(1) Hydrogen Atom Transfer (HAT)

$$
\text { Sterol }+\mathrm{R}^{\bullet} \rightarrow\left[\text { Sterol }_{(-\mathrm{H})}\right] \bullet+\mathrm{HR}
$$

(2) Electron Transfer (ET)

$$
\text { Sterol }+\mathrm{R}^{\bullet} \rightarrow[\text { Sterol }]^{\bullet+}+\mathrm{R}^{-}
$$

(3) Electron Transfer followed by Proton Transfer (ET-PT)

$$
\text { Sterol }+\mathrm{R}^{\bullet} \rightarrow\left[\text { Sterol }^{\bullet+}+\mathrm{R}^{-} \rightarrow\left[\text { Sterol }_{(-\mathrm{H})}\right]^{\bullet}+\mathrm{HR}\right.
$$

(4) Radical Adduct Formation (RAF)

$$
\text { Sterol }+\mathrm{R}^{\bullet} \rightarrow[\text { Sterol-R }]^{\bullet}
$$

The HAT and ET-PT mechanisms lead to the formation of the same end-products, namely free-radical sterols. However, ET-PT involves an intermediary step that corresponds to the ET reaction with the formation of a radical cation from sterol. The RAF mechanism consists of the formation of a bond between the radical and the sterol, allowing for the stabilization of the radical. In a previous thermodynamic study of ergosterol, it was shown that the Gibbs free energies of the RAF reactions were endergonic or close to zero, meaning that these reactions are unfavorable [34]. Therefore, we did not consider these reactions in our study. We first assessed the stability of the sterol radical cations and their electronic structure.

The radical cations (RC) formed from neutral sterols by the loss of an electron are high-energy intermediates with $\Delta \mathrm{G}$ values higher than $500 \mathrm{~kJ} / \mathrm{mol}$ (Figure $5 \mathrm{a}$ ). The higher stability of the ergosterol and cholesta-5,7,24-trienol radical cations with respect to the zymosterol one comes from the fact that the single electron is more delocalized on ergosterol and cholesta-5,7,24-trienol radical cations, as shown by the spin density maps of Figure $5 b$. This larger delocalization comes from the conjugated double bond present in ergosterol and cholesta-5,7,24-trienol, but not in zymosterol.

The computed dipoles suggest that upon oxidation, the ergosterol RC may move in the cell membrane (between the core and the surface of the membrane) because of an increased polarity between the stable molecules and their respective RCs. In addition, the higher ionization energy for the ergosterol free radical indicates a greater electronic stability of this species compared with the zymosterol free radical. It is also interesting to compare the Map of Electrostatic Potential (MEP; Figure 5c), which illustrates the presence of partial charges on the molecule. The electrostatic potential of molecules is also related to the molecule polarity. The lower electrostatic potential of zymosterol in comparison with ergosterol confirms the difference of polarity between the two sterol molecules. Radical cations are more polar than their neutral counterpart, as evidenced by their much higher dipoles (Figure 5a): this higher polarity of the ergosterol RC facilitates its displacement to a more polar region of the lipid bilayer. It is worth noting that the radical cations of ergosterol are much more polar than that of zymosterol.

We then computed the Gibbs free energy evolution for the reaction of each sterol with the DPPH radical, as gathered in Figure 5d. The ET step with DPPH is endergonic for all three sterols (Figure 5b). This indicates that the ET reaction will only occur if it is followed by the exergonic proton-transfer step. Interestingly, the relative free energies of the radical cation intermediate and the final radical followed the same order: cholesta-5,7,24-trienol < ergosterol < zymosterol. Consequently, computational results were in agreement with the fact the ergosterol reacts faster with $\mathrm{DPPH}^{\circ}$ than zymosterol (Figure 4).

While a full mechanistic study is beyond the scope of this article, we characterized the transition state for the HAT reaction between ergosterol and the DPPH radical 
(see Appendix C). The activation barrier is equal to $236.4 \mathrm{~kJ} / \mathrm{mol}$, much higher than those estimated for the ET step. Therefore, the ET-PT mechanism seems to be the most plausible for the antioxidant mechanism of these sterols.

a

\begin{tabular}{|c|ccc|ccc|ccc|}
\hline \multicolumn{4}{|c}{ Ergosterol } & \multicolumn{3}{c}{ Zymosterol } & Cholesta-5,7,24-trienol \\
& Neutral & $\begin{array}{c}\text { Rad. } \\
\text { Cation }\end{array}$ & Radical & Neutral & $\begin{array}{c}\text { Rad. } \\
\text { Cation }\end{array}$ & Radical & Neutral & $\begin{array}{c}\text { Rad. } \\
\text { Cation }\end{array}$ & Radical \\
\hline $\begin{array}{c}\text { Ionization Gibbs } \\
\text { Free energy } \\
\text { (kJ/mol) }\end{array}$ & $\mathbf{5 3 6 . 8}$ & - & - & $\mathbf{5 7 1 . 3}$ & - & - & $\mathbf{5 2 4 . 5}$ & - & - \\
\hline Dipole (Debye) & $\mathbf{1 . 8 5}$ & $\mathbf{1 4 . 0 3}$ & $\mathbf{5 . 8 3}$ & $\mathbf{2 . 4 6}$ & $\mathbf{6 . 0 6}$ & $\mathbf{3 . 8 5}$ & $\mathbf{1 . 5 6}$ & $\mathbf{1 3 . 4 0}$ & $\mathbf{8 . 0 8}$ \\
\hline
\end{tabular}
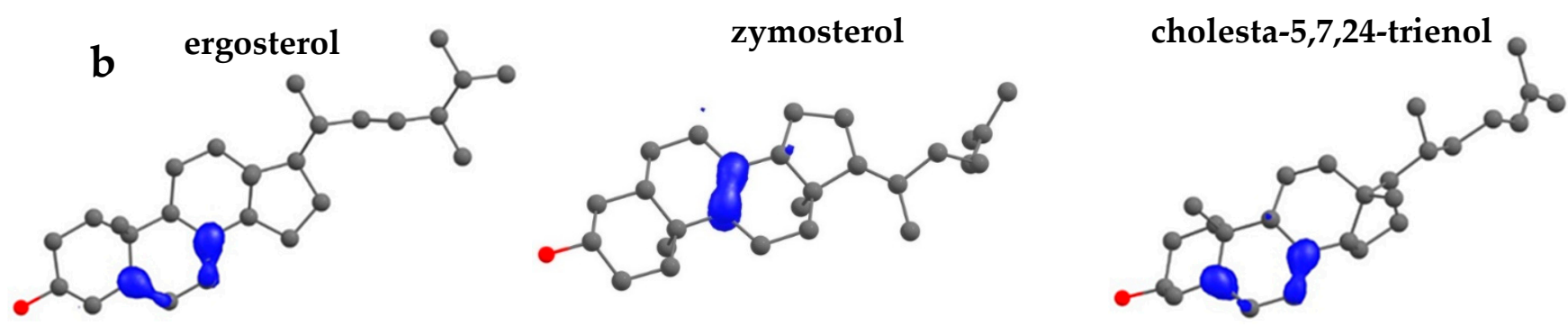

C

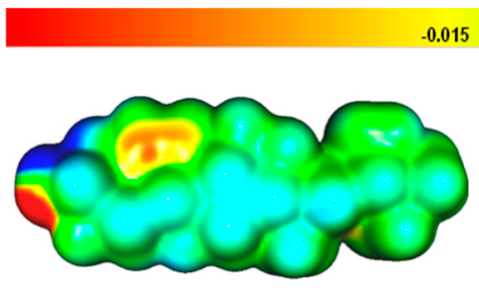

ergosterol
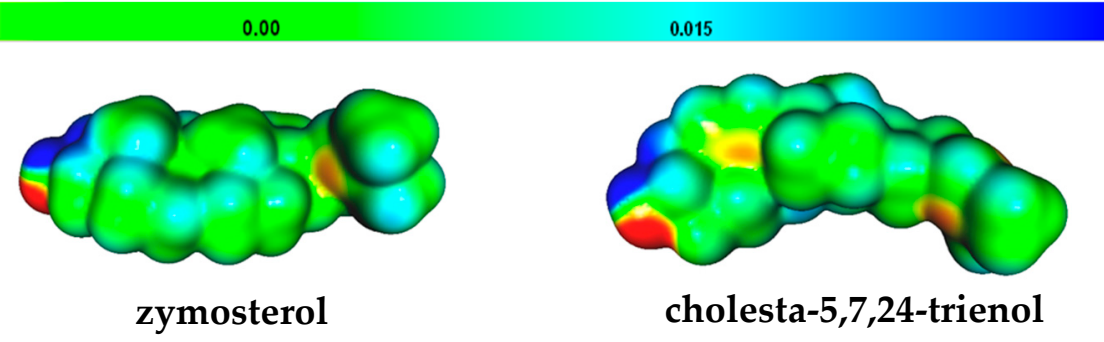

d

\begin{tabular}{|c|c|c|c|c|}
\hline & DPPH $^{\bullet}+$ Sterol & Activation Barrier $^{[a]}$ & $\mathbf{D P P H}^{-}+$Sterol $^{\bullet+}$ & DPPH-H + Sterol $_{(-\mathrm{H})}{ }^{\bullet}$ \\
\hline Ergosterol & 0 & 109.6 & 101.8 & -46.3 \\
\hline Zymosterol & 0 & 144.7 & 136.4 & -20.5 \\
\hline Cholesta-5,7,24-trienol & 0 & 94.5 & 90.4 & -53.9 \\
\hline
\end{tabular}

Figure 5. Computational study of the antioxidant properties of ergosterol, zymosterol, and cholesta-5,7,24-trienol. (a) B3LYP/6-311G(2d,p)-calculated properties for ergosterol, zymosterol, and cholesta-5,7,24-trienol species. (b) Representation of spin density of the radical cations of ergosterol, zymosterol, and cholesta-5,7,24-trienol. (c) Electrostatic potential maps of sterols. Blue indicates more positive regions; red indicates more negative regions. (d) Relative Gibbs free energies (at $298 \mathrm{~K}$ ) in kJ/mol of the main intermediates for the reaction of DPPH radicals with ergosterol, zymosterol, and cholesta-5,7,24-trienol species. The activation barrier for the electron transfer was estimated using the Marcus theory. 
From these results, we can conclude that the characteristics obtained in the oxidation modelling of these sterols indicate that cholesta-5,7,24-trienol and ergosterol, but also to a lesser extent zymosterol, can act as antioxidants via the ET-PT mechanism. ET greatly increases the polarity of sterols and could induce the migration of sterol RC towards the surface of the lipid bilayer, a location that may favor deprotonation to complete the ET-PT mechanism.

\section{Discussion}

The conventional approach to assessing the role of sterol in yeasts is the use of mutant strains in which the genes involved in the EBP are deleted. The last five genes of this pathway are non-essential and their deletion leads to mutant strains that accumulate different sterols [32]. In this way, it was shown that ergosterol is involved in yeast resistance to chemical and physical perturbations $[9,17,35,36]$. In the present study, a comparison of the resistance of $\operatorname{erg} 6 \Delta, \operatorname{erg} 2 \Delta \operatorname{erg} 6 \Delta$, and WT strains revealed that the accumulation of zymosterol in place of other sterols, namely ergosterol, made yeasts more sensitive to oxidative perturbations induced by $\mathrm{t}-\mathrm{BOOH}$ (Figure 2a), a chemical oxidant that targets membrane lipids. The high susceptibility of the mutant strains was correlated with the loss of plasma membrane integrity (Figure 2b). Peroxidation of phospholipids modifies their structural characteristics, which leads to alterations in the molecular organization of the plasma membrane. Oxidative agents react with the unsaturated acyl chains of phospholipids, leading to the formation of lipid hydroperoxides. The presence of hydroperoxides in the membrane causes an increase in water permeability and the modification of membrane order and fluidity [37-39]. When extensive peroxidation occurs, the formation of pores in membrane has been reported $[40,41]$. The degree of plasma membrane fatty acid unsaturation and the yeast sensitivity to oxidative stress are closely related [42]. The fatty acid profiles of the different strains of our study were very similar (Figure 1b), with a high content of mono-unsaturated fatty acids. Thus, the difference in the sensitivity between strains cannot be explained by the difference in the unsaturation of fatty acids. Three mechanisms could explain the higher resistance of the WT strains compared with the EBP mutant strains.

(i) The first mechanism is related to the structural effect of sterols. In contrast to the destabilizing effect of lipid peroxidation products, sterols could exert a stiffening effect on the plasma membrane. It has been reported that the addition of cholesterol to the lipid bilayer could maintain the structure of lipoperoxidized membranes based on its ability to counteract fatty acid disordering [43]. This effect could probably be related to the nature of the sterol molecule and could explain the greater destabilization of membranes during the accumulation of oxidized phospholipids in the mutants compared with the WT strains.

(ii) A second hypothetical mechanism is based on the antioxidant activity of sterols themselves. It is well known that sterols are able to be oxidized and the literature dealing with oxysterols is increasingly abundant [44]. Several authors have suggested that sterols could be the point of weakness for cells during oxidative perturbations $[45,46]$. However, another hypothesis proposes that the oxidation of membrane sterols could avoid the peroxidation of phospholipids. Outside the cellular context, it has been shown that the presence of sterols in phospholipid mixtures prevents phospholipid peroxidation. The protective effect of sterols depends on the nature of the sterols [47], and ergosterol could fulfill this function $[19,48]$. The hypothesis that sterols act as endogenous cell antioxidants has been proposed for cholesterol [49] and ergosterol [9]. However, this activity has not yet been clearly demonstrated.

(iii) Finally, the higher sensitivity of the EBP mutant strains compared with the WT could originate from the effect of erg6 and erg2 gene deletion on metabolic pathways or regulatory networks other than the ergosterol biosynthetic pathway. Indeed, yeasts have multiple antioxidant systems that can act to protect cells from oxidative damage [50]. Rather than being the result of an antioxidant effect of ergosterol, the better survival of the WT strains compared with the mutants could be explained by an indirect effect of the deletion of a gene in the EBP on one or more of these antioxidant systems. In a study by 
Gazdag and colleagues [51], it was concluded that the unbalanced redox state of an erg mutant $(\operatorname{erg} 5 \Delta)$ could be at the origin of the higher sensitivity to $\mathrm{t}-\mathrm{BOOH}$ of the mutant in comparison with the wild type strain. The redox state of the mutants used in our study (erg6 $\Delta$ and $\operatorname{erg} 2 \Delta \operatorname{erg} 6 \Delta$ ) could also display this unbalance.

In our study, the addition of zymosterol, cholesta-5,7,24-trienol, or ergosterol in liposomes (prepared from natural polar lipid extracts of S. cerevisiae) led to a decrease in the rate of phospholipid oxidation induced by cumene hydroperoxide and haemin (Figure 3), suggesting that sterols themselves protect phospholipids. This effect was greater for cholesta-5,7,24-trienol and ergosterol than for zymosterol, without reaching the protective level of tocopherol. This result is in agreement with a previous study that showed that ergosterol inhibits iron-dependent liposomal lipid peroxidation [48]. To our knowledge, the protective effect of cholesta-5,7,24-trienol has not been studied. These in vitro liposome experiments allowed us to show the antioxidant properties of sterols in a membrane context without other cellular contributing factors. A comparison of the structural effects of the different sterols and tocopherol on liposomes showed that ergosterol slightly increases the rigidity of the lipid bilayer, whereas cholesta-5,7,24-trienol and zymosterol strongly rigidify the membrane. The rigidifying effect of zymosterol was similar to tocopherol (Figure $3 b$ ). Thus, the rigidifying effect of sterols and phospholipid protection from oxidation were not correlated. This indicates that the antioxidant property of sterols is not strictly related to their structural effects.

Beyond in vivo experiments, the antioxidant properties of molecules can be assessed by in vitro and in silico approaches. In our study, we showed that sterols display a DPPH radical scavenging activity, with a greater activity for ergosterol than for zymosterol (Figure 4). Computational studies based on quantum chemistry have been shown to be a very effective tool to provide evidence and to understand the structure-activity relationship of different compounds. This method has been widely used to explain the antioxidant properties of numerous molecules. Quantum-chemical calculations revealed that ergosterol, zymosterol, and cholesta-5,7,24-trienol could react with radical species and exhibit antioxidant properties by means of an ET-PT mechanism. In this mechanism, radical cations from sterols are first formed by the loss of an electron and are then transformed into free radicals by proton abstraction. However, zymosterol radical cation is less stable than the radical cations of ergosterol and cholesta-5,7,24-trienol (Figure 5d). This difference is based on the presence of two conjugated double bonds in the B-ring of the ergosterol and cholesta-5,7,24-trienol molecules, which allows for the delocalization of unpaired electrons over several atoms (Figure 5b), thereby conferring greater stability on the radicals compared with localized radicals. By their reaction with radical species, sterols and mainly sterols having two conjugated double bonds of the B-ring, as ergosterol and cholesta-5,7,24-trienol, could prevent phospholipid peroxidation in the lipid bilayer. A previous study showed that sterols exhibited a higher reactivity than fatty acids with a hydroxyethyl radical [52].

The basis of the specificity of sterols in each eukaryotic kingdom is intriguing. In particular, the reason for ergosterol accumulation by fungi is unclear, because its synthesis requires more energy than that of cholesterol [7], and structure-function studies did not show any benefits of ergosterol compared with cholesterol [53]. The results of our study revealed that sterols are not only structural compounds of the plasma membrane of eukaryotic cells, but can also display antioxidant properties. These are particularly remarkable for ergosterol and cholesta-5,7,24-trienol, whose structure contains two conjugated double bonds. In vivo experiments performed on yeasts revealed that the $\operatorname{erg} 2 \Delta \operatorname{erg} 6 \Delta$ strain, for which sterols with two conjugated double bonds represented $4 \%$ of sterols ( $3 \%$ cholesta-5,7,24-trienol and 1\% ergosta-5,7-dienol), was the most sensitive strain tested in our study (Figures 1 and 2). Even if more resistant than $\operatorname{erg} 2 \Delta \operatorname{erg} 6 \Delta$, the $\operatorname{erg} 6 \Delta$ strain was more sensitive than the wild type strain (Figure 2). A possible explanation for this result could be the difference in the proportion of sterols with two conjugated double bonds. Indeed, the $\operatorname{erg} 6 \Delta$ strain presented $69 \%$ of sterols with two conjugated double bonds ( $23 \%$ cholesta-5,7,22,24-tetraenol and $46 \%$ cholesta-5,7,24-trienol), while the wild type strain 
presented 87\% (77\% ergosterol, 8\% ergosta-5,7-dienol, and 2\% ergosta-5,7,9(11),22-tetraenol; Figure 1). In the cellular context of yeasts, cholesta-5,7,24-trienol is not accumulated in such a large proportion as ergosterol is. This sterol, as with other ergosterol precursors accumulated by the EBP yeast mutants, is not mainly accumulated by environmental yeasts, which accumulate ergosterol in a large proportion. Therefore, ergosterol may be the most efficient molecule to both provide structural functions of the yeast plasma membrane and to protect it from oxidation. Its hydrophobic nature could result in its displaying scavenging activity in the vicinity of the lipids' double bounds. A recent study suggested that ergosterol could interact preferentially with mono-unsaturated fatty acids, whereas cholesterol is able to interact with saturated lipids [54]. In such a context, the presence of ergosterol close to the unsaturated phospholipid acyl chains of yeast may constitute a key element explaining the uncommon resistance of yeast to desiccation. These results reinforce that ergosterol has been retained during evolution in late branching fungi because it serves as a consensus sterol, being able to satisfy both the structural and antioxidant functions [9]. These functions are crucial for those organisms that live in interfacial habitats where they experience hydric and oxidative perturbations. All of these knowledge elements support the Brown and Galea hypothesis, which postulates that sterols are an adaptation to aerobic life $[55,56]$.

The results of our study strongly suggest that ergosterol is an antioxidant molecule that prevents phospholipid oxidation in the cellular context. This role has rarely been associated with sterols, and it will be interesting to study this function in cholesterol and phytosterols. In eukaryotic cells, sterols are not homogeneously distributed in the plasma membrane, but enrich specific membrane domains. In mammalian and plant cells, these domains, called lipid rafts, are very small (not visualizable by optical microscopy) and transitory in time [57]. The plasma membrane of yeasts contains large and stable domains called microdomains, among which some are enriched in ergosterol [58]. These ergosterol-rich microdomains could be hypothetically considered as antioxidant islets in the yeast plasma membrane. Moreover, a study focusing on yeast plasma membrane organization showed that ergosterol is excluded from sphingolipid-enriched gel domains [59]. In this model, ergosterol is surrounded by unsaturated phospholipids. Thus, the location of ergosterol in the vicinity of acyl chain unsaturation could be particularly favorable for preventing phospholipid oxidation. Future investigations should take into account the antioxidant properties of sterols to clarify their roles in their local context, i.e., the hydrophobic core of the phospholipid bilayer and cell membrane domains.

\section{Conclusions}

By using in vitro and in silico approaches, we showed in our study that ergosterol acts as an antioxidant molecule that could be involved in yeast resistance to oxidation. In the cellular context, the antioxidant function of ergosterol could be of prime importance for yeasts and other fungi to resist oxidative stress. Specifically, free ergosterol accumulated in the plasma membrane of fungi cells could allow for the protection of phospholipids against oxidative perturbations. Thanks to a computational study based on quantum chemistry, we demonstrated that the antioxidant ability of ergosterol operates through an electron transfer, followed by proton transfer mechanism, and is related to the presence of the two conjugated double bonds of the B-ring of the sterol structure. Outside the cellular context, ergosterol might be used as a natural antioxidant molecule to prevent the oxidative degradation of foods. Finally, the antioxidant function of the ergosterol molecule could play a role in the incompletely understood beneficial effects of some mushrooms on health.

Author Contributions: Conceptualization, S.D., P.G., F.S.-P., P.C. and L.B.; methodology, S.D., P.F.-L., R.G.C. and L.B.; validation, S.D., P.C. and L.B.; formal analysis, P.F.-L. and C.G.; investigation, S.D., P.F.-L., R.G.C., C.L., F.Y., O.A.J. and P.C.; funding acquisition, L.B.; project administration, S.D. and L.B.; Supervision, S.D. and L.B.; Visualization, S.D., P.F.-L. and C.L.; writing-original draft, S.D., P.F.-L., R.G.C. and L.B.; writing-review and editing, C.L., C.G., P.G.-P., P.G., F.S.-P. and P.C. All authors have read and agreed to the published version of the manuscript. 
Funding: This work was supported by the Regional Council of Bourgogne, Franche Comté, the "Fonds Européen de DEveloppement Régional (FEDER BG0013217)" and AgroSup Dijon. Calculations were performed using HPC resources from DNUM-CCUB (Université de Bourgogne).

Institutional Review Board Statement: Not applicable.

Informed Consent Statement: Not applicable.

Data Availability Statement: Data are contained within the article.

Acknowledgments: We are grateful to H. Riezman (University of Geneva, Switzerland) for providing the RH448 the erg2 $\Delta \operatorname{erg} 6 \Delta$ yeast strains. The authors thank the Dimacell Imaging Resource Center for technical support during spectrofluorimetry experiments. The authors also wish to thank MetaboHubBordeaux platform, funded by grant MetaboHUB-ANR-11-INBS-0010, for the lipidomic analyses.

Conflicts of Interest: Authors declare that they have no conflict of interest.

\section{Appendix A}

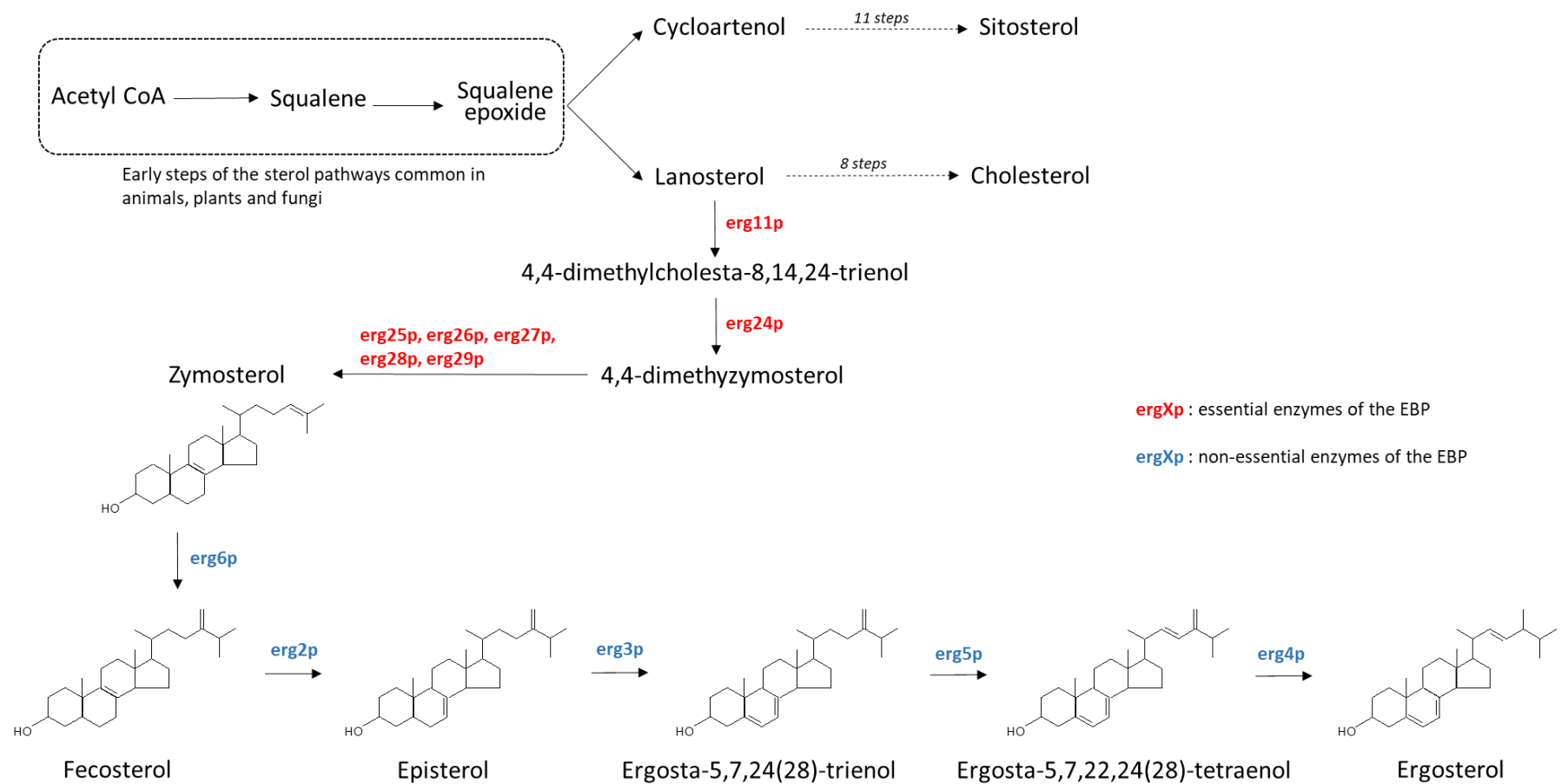

Figure A1. Schematic representation of the ergosterol biosynthesis pathway from acetyl CoA. Plants, animals, and fungi have a common early sterol synthetic pathway up to squalene epoxide. After this compound, cycloartenol is produced in plants, whereas squalene epoxide gives lanosterol in animals and fungi. The end-products of the sterol pathways are sitosterol, cholesterol, and ergosterol for plants, animals, and fungi, respectively. The final enzymes involved in the ergosterol biosynthesis (ergXp) are described.

\section{Appendix B}

Complementary to the experiment consisting in placing yeasts in contact of $\mathrm{t}-\mathrm{BOOH}$ in PBS medium, yeast resistance to oxidation was assessed by plating a yeast suspension on solid growth YPD medium containing low concentrations of tert-butyl hydroperoxide (t-BOOH; $0.1,0.5$, or $1 \mathrm{mM}$ ) and the growth of the strains compared after $48 \mathrm{~h}$. Because of the very high sensitivity of the $\operatorname{erg} 2 \Delta \operatorname{erg} 6 \Delta$ double mutant, no growth was observed regardless of the $\mathrm{t}-\mathrm{BOOH}$ concentration (data not shown). WT BY 4742 strain growth was weakly affected by the presence of $\mathrm{t}-\mathrm{BOOH}$ : at the highest concentration used $(1 \mathrm{mM})$, the number of colony-forming units (CFU) was $70 \%$ of that in the control (without $\mathrm{t}-\mathrm{BOOH}$ ). In contrast, the growth of the $\operatorname{erg} 6 \Delta$ strain decreased dramatically with increasing concen- 
trations of $\mathrm{t}-\mathrm{BOOH}$ and reached $0.008 \%$ of the control at a concentration of $0.5 \mathrm{mM}$. No growth was observed at $1 \mathrm{mM}$.

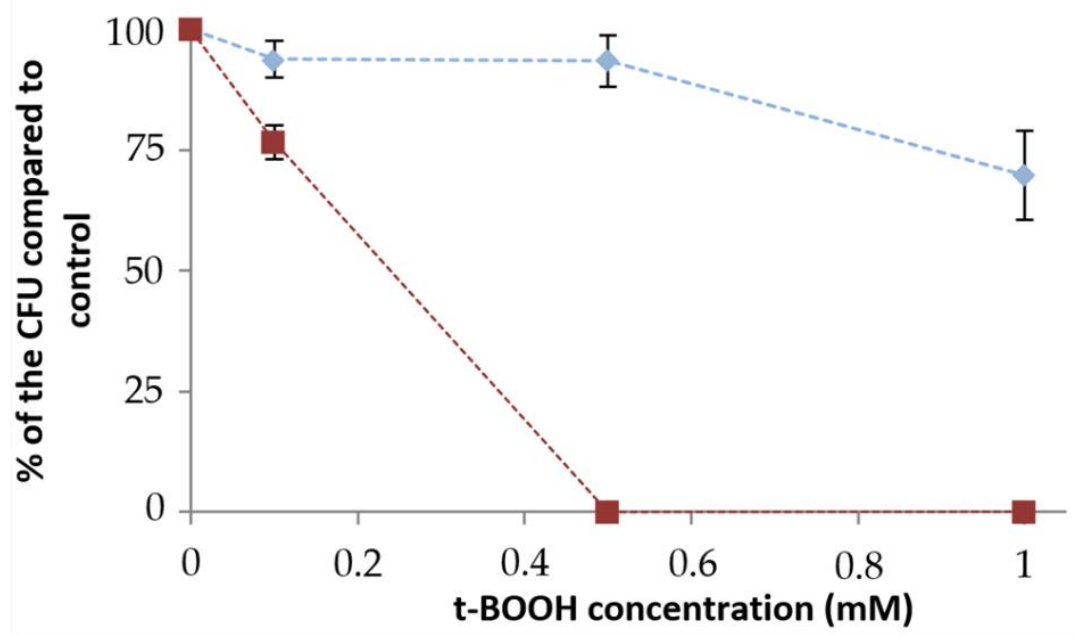

\section{Wild Type BY4742 erg6 $\Delta$

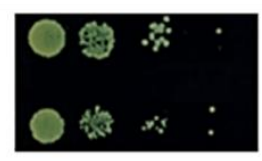

Control $(0 \mathrm{mM})$

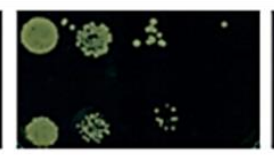

$0.1 \mathrm{mM}$

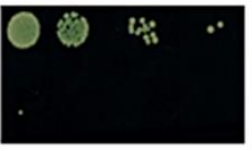

$0.5 \mathrm{mM}$

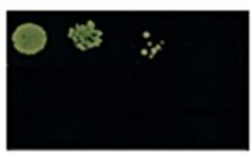

$1 \mathrm{mM}$

Figure A2. Tolerance of $S$. cerevisiae to various concentrations of $\mathrm{t}-\mathrm{BOOH}$ in the growth medium. WT BY4742 $(\diamond)$ and $\operatorname{erg} 6 \Delta(\square)$ strains of $S$. cerevisiae are grown for $48 \mathrm{~h}$ at $25^{\circ} \mathrm{C}$ in a yeast extractpeptone-dextrose (YPD) medium supplemented with various concentrations of $\mathrm{t}$ - $\mathrm{BOOH}(0,0.1,0.5$, or $1 \mathrm{mM}$ ). Cells were spotted at different ten-fold dilutions (from $10^{-1}$ to $10^{-4}$ ) from the initial suspension at $\mathrm{OD}_{600 \mathrm{~nm}}=0.5$. Data are presented as mean values \pm standard deviation of three independent experiments.

\section{Appendix C}

Appendix C.1. Estimation of the Electron Transfer Activation Free Energy

Electron transfers are usually described using collective reaction coordinates, as first described by Marcus [60]. In the Marcus theory, the activation free energy is as follows:

$$
\Delta_{r} G^{\ddagger}=\frac{\lambda}{4}\left(1+\frac{\Delta G_{E T}}{\lambda}\right)^{2}
$$

$\Delta G_{E T}$ is the Gibbs free energy of electron transfer $(E T)$ reaction and $\lambda$ is the reorganization energy. The reorganization energy was calculated as

$$
\lambda=\Delta E_{E T}-\Delta G_{E T}
$$

where $\Delta E_{E T}$ is the nonadiabatic energy difference between the reactants ( $\left.\mathrm{DPPH} \mathrm{H}^{\bullet} \mathrm{sterol}\right)$ and the vertical products (i.e., $\mathrm{DPPH}^{-}+$Sterol $^{\bullet+}$ in the same geometry as the reactants) [61].

\section{Appendix C.2. Bond Dissociation Energies $(\mathrm{kJ} / \mathrm{mol})$ for Several H Atoms}

By inspecting the spin density (with a low iso-value of 0.004), it appeared that many $\mathrm{CH}$ bonds were polarized and could thus lead to the formation of different radical species. We thus computed the bond dissociation energies (BDE) of these bonds to obtain the relative stabilities of the possible radical molecules: the most stable radical corresponds to the lowest BDE (show in green). 


\section{Ergosterol}

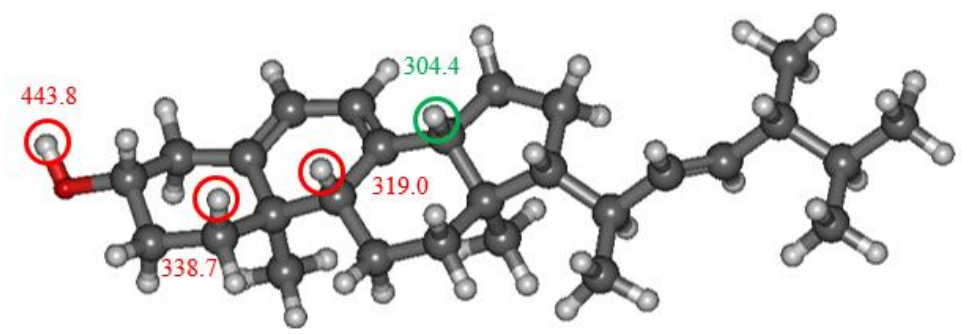

\section{Zymosterol}

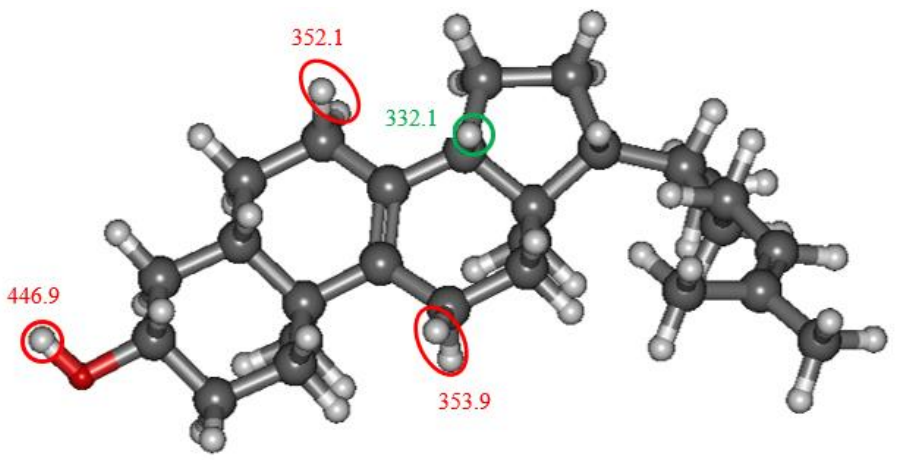

\section{Cholesta-5,7,24-trienol}

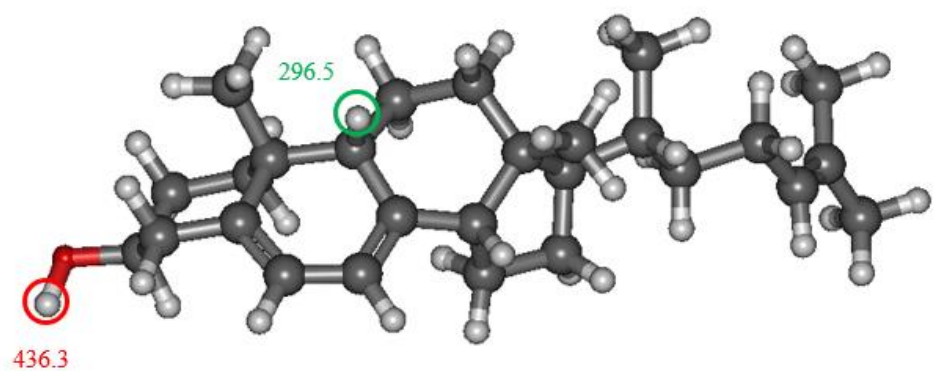

Appendix C.3. Transition State for the H Atom Tranfer from Ergosterol Radical Cation to DPPH

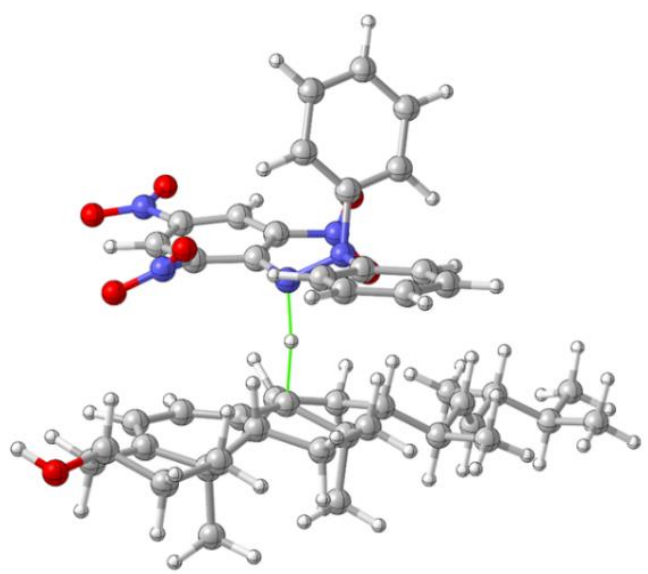




\section{References}

1. Nes, W.D. Biosynthesis of Cholesterol and Other Sterols. Chem. Rev. 2011, 111, 6423-6451. [CrossRef]

2. Tanret, C. Sur Un Nouveau Principle Immediate de l'ergot Deseigle Ergosterine. CR Seances Acad. Sci. 1889, 108, 98-100.

3. Van Meer, G.; Voelker, D.R.; Feigenson, G.W. Membrane Lipids: Where They Are and How They Behave. Nat. Rev. Mol. Cell Biol. 2008, 9, 112-124. [CrossRef]

4. Gray, K.C.; Palacios, D.S.; Dailey, I.; Endo, M.M.; Uno, B.E.; Wilcock, B.C.; Burke, M.D. Amphotericin Primarily Kills Yeast by Simply Binding Ergosterol. Proc. Natl. Acad. Sci. USA 2012, 109, 2234-2239. [CrossRef]

5. Mercer, E.I. Inhibitors of Sterol Biosynthesis and Their Applications. Prog. Lipid Res. 1993, 32, 357-416. [CrossRef]

6. Jordá, T.; Puig, S. Regulation of Ergosterol Biosynthesis in Saccharomyces Cerevisiae. Genes 2020, 11, 795. [CrossRef]

7. Parks, L.W.; Casey, W.M. Physiological Implications of Sterol Biosynthesis in Yeast. Annu. Rev. Microbiol. 1995, 49, 95-116. [CrossRef]

8. Weete, J.D.; Abril, M.; Blackwell, M. Phylogenetic Distribution of Fungal Sterols. PLoS ONE 2010, 5, e10899. [CrossRef]

9. Dupont, S.; Lemetais, G.; Ferreira, T.; Cayot, P.; Gervais, P.; Beney, L. Ergosterol Biosynthesis: A Fungal Pathway for Life on Land? Evol. Int. J. Org. Evol. 2012, 66, 2961-2968. [CrossRef]

10. Dupont, S.; Rapoport, A.; Gervais, P.; Beney, L. Survival Kit of Saccharomyces Cerevisiae for Anhydrobiosis. Appl. Microbiol. Biotechnol. 2014, 98, 8821-8834. [CrossRef] [PubMed]

11. Dupont, S.; Beney, L.; Ritt, J.-F.; Lherminier, J.; Gervais, P. Lateral Reorganization of Plasma Membrane Is Involved in the Yeast Resistance to Severe Dehydration. Biochim. Biophys. Acta BBA-Biomembr. 2010, 1798, 975-985. [CrossRef]

12. Leslie, S.B.; Teter, S.A.; Crowe, L.M.; Crowe, J.H. Trehalose Lowers Membrane Phase Transitions in Dry Yeast Cells. Biochim. Biophys. Acta BBA Biomembr. 1994, 1192, 7-13. [CrossRef]

13. Rapoport, A.; Golovina, E.A.; Gervais, P.; Dupont, S.; Beney, L. Anhydrobiosis: Inside Yeast Cells. Biotechnol. Adv. 2019, 37, 51-67. [CrossRef]

14. Garre, E.; Raginel, F.; Palacios, A.; Julien, A.; Matallana, E. Oxidative Stress Responses and Lipid Peroxidation Damage Are Induced during Dehydration in the Production of Dry Active Wine Yeasts. Int. J. Food Microbiol. 2010, 136, 295-303. [CrossRef] [PubMed]

15. de Jesus Pereira, E.; Panek, A.D.; Eleutherio, E.C.A. Protection against Oxidation during Dehydration of Yeast. Cell Stress Chaperones 2003, 8, 120. [CrossRef]

16. Piette, J. New Trends in Photobiology: Biological Consequences Associated with DNA Oxidation Mediated by Singlet Oxygen. J. Photochem. Photobiol. B 1991, 11, 241-260. [CrossRef]

17. Dupont, S.; Beney, L.; Ferreira, T.; Gervais, P. Nature of Sterols Affects Plasma Membrane Behavior and Yeast Survival during Dehydration. Biochim. Biophys. Acta BBA-Biomembr. 2011, 1808, 1520-1528. [CrossRef] [PubMed]

18. Heleno, S.A.; Rudke, A.R.; Calhelha, R.C.; Carocho, M.; Barros, L.; Gonçalves, O.H.; Barreiro, M.F.; Ferreira, I.C. Development of Dairy Beverages Functionalized with Pure Ergosterol and Mycosterol Extracts: An Alternative to Phytosterol-Based Beverages. Food Funct. 2017, 8, 103-110. [CrossRef] [PubMed]

19. Shao, S.; Hernandez, M.; Kramer, J.K.; Rinker, D.L.; Tsao, R. Ergosterol Profiles, Fatty Acid Composition, and Antioxidant Activities of Button Mushrooms as Affected by Tissue Part and Developmental Stage. J. Agric. Food Chem. 2010, 58, 11616-11625. [CrossRef] [PubMed]

20. Munn, A.L.; Heese-Peck, A.; Stevenson, B.J.; Pichler, H.; Riezman, H. Specific Sterols Required for the Internalization Step of Endocytosis in Yeast. Mol. Biol. Cell 1999, 10, 3943-3957. [CrossRef] [PubMed]

21. Sousa-Lopes, A.; Antunes, F.; Cyrne, L.; Marinho, H.S. Decreased Cellular Permeability to H2O2 Protects Saccharomyces Cerevisiae Cells in Stationary Phase against Oxidative Stress. FEBS Lett. 2004, 578, 152-156. [CrossRef]

22. Biryukova, E.N.; Medentsev, A.G.; Arinbasarova, A.Y.; Akimenko, V.K. Tolerance of the Yeast Yarrowia Lipolytica to Oxidative Stress. Microbiology 2006, 75, 243-247. [CrossRef]

23. Bangham, A.D.; Standish, M.M.; Watkins, J.C. Diffusion of Univalent Ions across the Lamellae of Swollen Phospholipids. J. Mol. Biol. 1965, 13, 238-IN27. [CrossRef]

24. Xie, J.; Schaich, K.M. Re-Evaluation of the 2, 2-Diphenyl-1-Picrylhydrazyl Free Radical (DPPH) Assay for Antioxidant Activity. J. Agric. Food Chem. 2014, 62, 4251-4260. [CrossRef]

25. Fadda, A.; Serra, M.; Molinu, M.G.; Azara, E.; Barberis, A.; Sanna, D. Reaction Time and DPPH Concentration Influence Antioxidant Activity and Kinetic Parameters of Bioactive Molecules and Plant Extracts in the Reaction with the DPPH Radical. J. Food Compos. Anal. 2014, 35, 112-119. [CrossRef]

26. Sánchez-Moreno, C.; Larrauri, J.A.; Saura-Calixto, F. A Procedure to Measure the Antiradical Efficiency of Polyphenols. J. Sci. Food Agric. 1998, 76, 270-276. [CrossRef]

27. Boissy, G.; O’Donohue, M.; Gaudemer, O.; Perez, V.; Pernollet, J.-C.; Brunie, S. The 2.1 \AA Structure of an Elicitin-Ergosterol Complex: A Recent Addition to the Sterol Carrier Protein Family. Protein Sci. 1999, 8, 1191-1199. [CrossRef]

28. Tomasi, J.; Mennucci, B.; Cammi, R. Quantum Mechanical Continuum Solvation Models. Chem. Rev. 2005, 105, 2999-3094. [CrossRef] [PubMed]

29. Frisch, M.J.; Trucks, G.W.; Schlegel, H.B.; Scuseria, G.E.; Robb, M.A.; Cheeseman, J.R.; Scalmani, G.; Barone, V.; Petersson, G.A.; Nakatsuji, H. Gaussian 16 Revision B. 01; Gaussian Inc.: Wallingford, CT, USA, 2016. 
30. Andrienko, G.A. Chemcraft. Graphical Software for Visualization of Quantum Chemistry Computations. 2010. Available online: http:/ / www.chemcraftprog.com (accessed on 12 May 2021).

31. Allouche, A.-R. Gabedit-A Graphical User Interface for Computational Chemistry Softwares. J. Comput. Chem. 2011, 32, 174-182. [CrossRef]

32. Heese-Peck, A.; Pichler, H.; Zanolari, B.; Watanabe, R.; Daum, G.; Riezman, H. Multiple Functions of Sterols in Yeast Endocytosis. Mol. Biol. Cell 2002, 13, 2664-2680. [CrossRef] [PubMed]

33. Drummen, G.P.; van Liebergen, L.C.; den Kamp, J.A.O.; Post, J.A. C11-BODIPY581/591, an Oxidation-Sensitive Fluorescent Lipid Peroxidation Probe:(Micro) Spectroscopic Characterization and Validation of Methodology. Free Radic. Biol. Med. 2002, 33, 473-490. [CrossRef]

34. Medina, M.E.; Iuga, C.; Trigos, Á. Mechanism and Kinetics of the Oxidative Damage to Ergosterol Induced by Peroxyl Radicals in Lipid Media: A Theoretical Quantum Chemistry Study. J. Phys. Org. Chem. 2016, 29, 196-203. [CrossRef]

35. Abe, F.; Hiraki, T. Mechanistic Role of Ergosterol in Membrane Rigidity and Cycloheximide Resistance in Saccharomyces Cerevisiae. Biochim. Biophys. Acta BBA-Biomembr. 2009, 1788, 743-752. [CrossRef]

36. Sanglard, D.; Ischer, F.; Parkinson, T.; Falconer, D.; Bille, J. Candida Albicans Mutations in the Ergosterol Biosynthetic Pathway and Resistance to Several Antifungal Agents. Antimicrob. Agents Chemother. 2003, 47, 2404-2412. [CrossRef]

37. Chen, J.J.; Yu, B.P. Alterations in Mitochondrial Membrane Fluidity by Lipid Peroxidation Products. Free Radic. Biol. Med. 1994, 17, 411-418. [CrossRef]

38. Itri, R.; Junqueira, H.C.; Mertins, O.; Baptista, M.S. Membrane Changes under Oxidative Stress: The Impact of Oxidized Lipids. Biophys. Rev. 2014, 6, 47-61. [CrossRef] [PubMed]

39. Mason, R.P.; Walter, M.F.; Mason, P.E. Effect of Oxidative Stress on Membrane Structure: Small-Angle X-Ray Diffraction Analysis. Free Radic. Biol. Med. 1997, 23, 419-425. [CrossRef]

40. Mertins, O.; Bacellar, I.O.; Thalmann, F.; Marques, C.M.; Baptista, M.S.; Itri, R. Physical Damage on Giant Vesicles Membrane as a Result of Methylene Blue Photoirradiation. Biophys. J. 2014, 106, 162-171. [CrossRef]

41. Van der Paal, J.; Neyts, E.C.; Verlackt, C.C.; Bogaerts, A. Effect of Lipid Peroxidation on Membrane Permeability of Cancer and Normal Cells Subjected to Oxidative Stress. Chem. Sci. 2016, 7, 489-498. [CrossRef] [PubMed]

42. Krasowska, A.; Chmielewska, L.; Prescha, A.; Váchová, L.; Sigler, K. Viability and Formation of Conjugated Dienes in Plasma Membrane Lipids OfSaccharomyces Cerevisiae, Schizosaccharomyces Pombe, Rhodotorula Glutinis AndCandida Albicans Exposed to Hydrophilic, Amphiphilic and Hydrophobic pro-Oxidants. Folia Microbiol. 2002, 47, 145-151. [CrossRef]

43. Megli, F.M.; Conte, E.; Ishikawa, T. Cholesterol Attenuates and Prevents Bilayer Damage and Breakdown in Lipoperoxidized Model Membranes. A Spin Labeling EPR Study. Biochim. Biophys. Acta BBA-Biomembr. 2011, 1808, 2267-2274. [CrossRef]

44. Luu, W.; Sharpe, L.J.; Capell-Hattam, I.; Gelissen, I.C.; Brown, A.J. Oxysterols: Old Tale, New Twists. Annu. Rev. Pharmacol. Toxicol. 2016, 56, 447-467. [CrossRef] [PubMed]

45. Böcking, T.; Barrow, K.D.; Netting, A.G.; Chilcott, T.C.; Coster, H.G.; Höfer, M. Effects of Singlet Oxygen on Membrane Sterols in the Yeast Saccharomyces Cerevisiae. Eur. J. Biochem. 2000, 267, 1607-1618. [CrossRef] [PubMed]

46. Casey, W.M.; Parks, L.W. A Role for Sterols in the Porphyrin Mediated Photosensitization of Yeast. Photochem. Photobiol. 1989, 50, 553-556. [CrossRef]

47. Gordon, M.H.; Magos, P. The Effect of Sterols on the Oxidation of Edible Oils. Food Chem. 1983, 10, 141-147. [CrossRef]

48. Wiseman, H. Vitamin D Is a Membrane Antioxidant Ability to Inhibit Iron-Dependent Lipid Peroxidation in Liposomes Compared to Cholesterol, Ergosterol and Tamoxifen and Relevance to Anticancer Action. FEBS Lett. 1993, 326, 285-288. [CrossRef]

49. Smith, L.L. Another Cholesterol Hypothesis: Cholesterol as Antioxidant. Free Radic. Biol. Med. 1991, 11, 47-61. [CrossRef]

50. Jamieson, D.J. Oxidative Stress Responses of the Yeast Saccharomyces Cerevisiae. Yeast 1998, 14, 1511-1527. [CrossRef]

51. Gazdag, Z.; Máté, G.; Čertik, M.; Türmer, K.; Virág, E.; Pócsi, I.; Pesti, M. Tert-Butyl Hydroperoxide-Induced Differing Plasma Membrane and Oxidative Stress Processes in Yeast Strains BY4741 and Erg5 $\Delta$. J. Basic Microbiol. 2014, 54, S50-S62. [CrossRef] [PubMed]

52. de Almeida, N.E.; de Aguiar, I.; de Zawadzki, A.; Cardoso, D.R. Kinetics and Thermodynamics of 1-Hydroxyethyl Radical Reaction with Unsaturated Lipids and Prenylflavonoids. J. Phys. Chem. B 2014, 118, 14278-14287. [CrossRef]

53. Shrivastava, S.; Chattopadhyay, A. Influence of Cholesterol and Ergosterol on Membrane Dynamics Using Different Fluorescent Reporter Probes. Biochem. Biophys. Res. Commun. 2007, 356, 705-710. [CrossRef]

54. Khmelinskaia, A.; Marquês, J.M.T.; Bastos, A.E.P.; Antunes, C.A.C.; Bento-Oliveira, A.; Scolari, S.; Lobo, G.M.d.S.; Malhó, R.; Herrmann, A.; Marinho, H.S.; et al. Liquid-Ordered Phase Formation by Mammalian and Yeast Sterols: A Common Feature With Organizational Differences. Front. Cell Dev. Biol. 2020, 8, 337. [CrossRef]

55. Brown, A.J.; Galea, A.M. Cholesterol as an Evolutionary Response to Living with Oxygen. Evol. Int. J. Org. Evol. 2010, 64, 2179-2183. [CrossRef]

56. Galea, A.M.; Brown, A.J. Special Relationship between Sterols and Oxygen: Were Sterols an Adaptation to Aerobic Life? Free Radic. Biol. Med. 2009, 47, 880-889. [CrossRef]

57. Rajendran, L.; Simons, K. Lipid Rafts and Membrane Dynamics. J. Cell Sci. 2005, 118, 1099-1102. [CrossRef] [PubMed]

58. Grossmann, G.; Opekarova, M.; Malinsky, J.; Weig-Meckl, I.; Tanner, W. Membrane Potential Governs Lateral Segregation of Plasma Membrane Proteins and Lipids in Yeast. EMBO J. 2007, 26, 1-8. [CrossRef] [PubMed] 
59. Aresta-Branco, F.; Cordeiro, A.M.; Marinho, H.S.; Cyrne, L.; Antunes, F.; de Almeida, R.F. Gel Domains in the Plasma Membrane of Saccharomyces Cerevisiae Highly Ordered, Ergosterol-Free, and Sphingolipid-Enriched Lipid Rafts. J. Biol. Chem. 2011, 286, 5043-5054. [CrossRef]

60. Marcus, R.A. Electron Transfer Reactions in Chemistry. Theory and Experiment. Rev. Mod. Phys. 1993, 65, 599-610. [CrossRef]

61. Nelsen, S.F.; Blackstock, S.C.; Kim, Y. Estimation of Inner Shell Marcus Terms for Amino Nitrogen Compounds by Molecular Orbital Calculations. J. Am. Chem. Soc. 1987, 109, 677-682. [CrossRef] 